\title{
Exploring Year 10 Samoan Students' Experiences of Teaching and Learning in the Mainstream English Classroom
}

By

Kalia Lautusi

\begin{abstract}
A thesis
submitted to the Victoria University of Wellington

in partial fulfilment of the requirements for the degree of

Master of Education

Victoria University of Wellington
\end{abstract}

2016 


\section{Abstract}

This research examined the ways in which twelve Year 10 Samoan students experienced teaching and learning in the mainstream English classroom. The study was guided by two questions: What perceptions do a group of Samoan students have of the strengths and skills they bring to the English classroom? And: How do these students see themselves as navigating teaching and learning in the English classroom drawing on these strengths?

The aim of the research was to further understand how skills Samoan students develop outside the English classroom are being used by the participants to create positive learning outcomes. As a way to prioritise Pacific student voices, the Pacific research methodology of talanoa was used to gather stories from the participants alongside observations of the English classroom.

Three major themes emerged from the findings - describing the need for interdependence, self-organisation, and fa'atua (or the value or reciprocal and mutually respectful relationships). Karlo Mila-Schaaf's (2010) concept of polycultural capital was used as a theoretical paradigm to interpret the findings. If educators can understand how a group is functioning well, and the conditions that allow this to happen, this knowledge can lead to benefits for other Pacific students. The study concludes with a consideration of what might happen if teachers consciously provide space for existing skills and strategies. 


\section{Table of Contents}

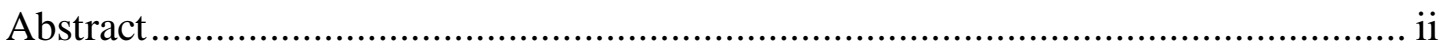

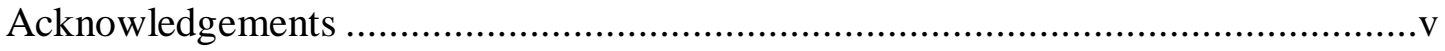

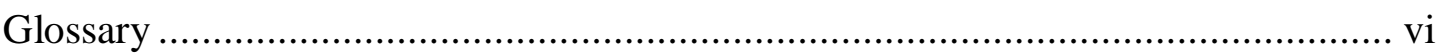

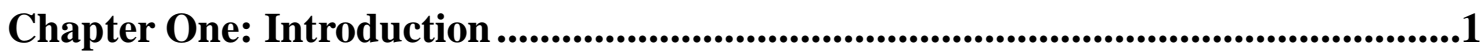

Personal Reflections on Learning and Teaching as a Samoan ..................................1

Use of the Term Pacific .....................................................................................

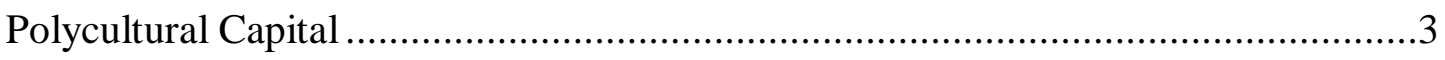

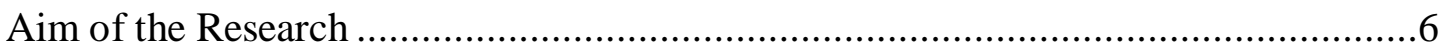

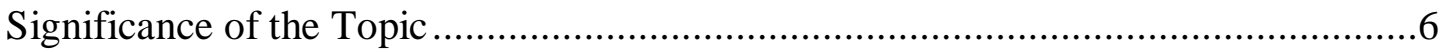

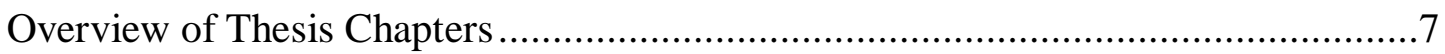

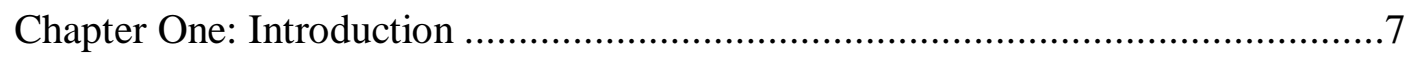

Chapter Two: Literature Review .....................................................................

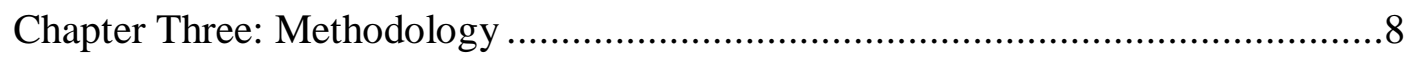

Chapter Four: Findings ....................................................................... 8

Chapter Five: Discussion and Recommendations ............................................

Chapter Two: Literature Review............................................................................................9

Government Initiatives, Plans and Policies ........................................................... 9

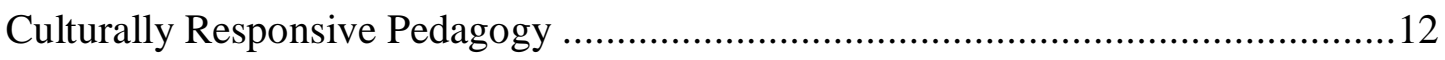

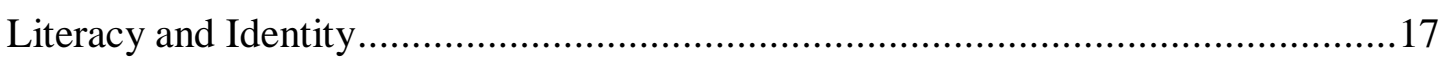

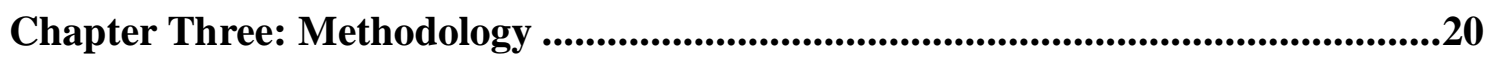

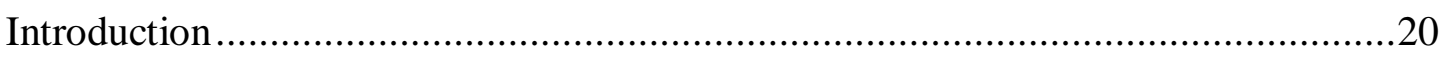

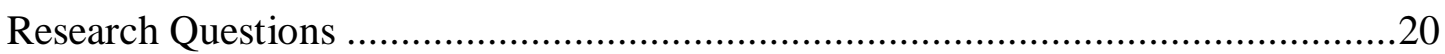

Negotiating Western and Pacific Methodologies ....................................................20

The Western Framework.............................................................................21

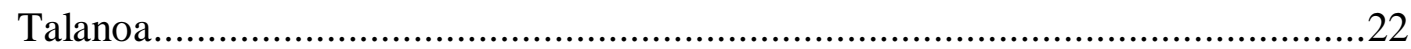

Teu le va: Negotiating the Relationships ......................................................24

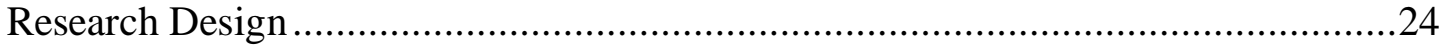

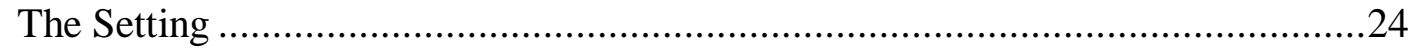

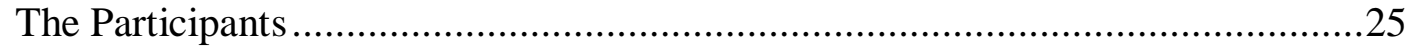

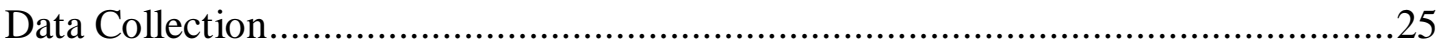

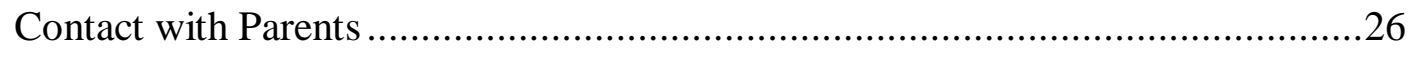

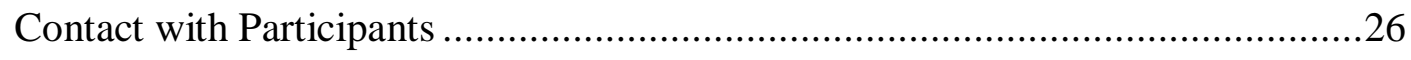

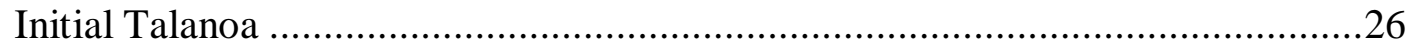

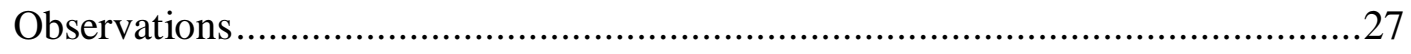

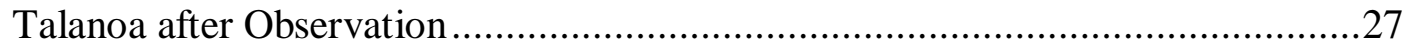




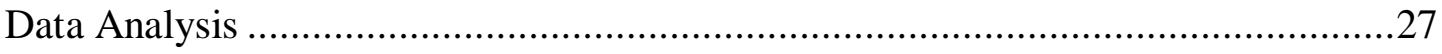

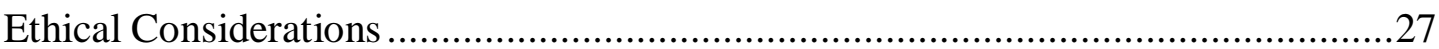

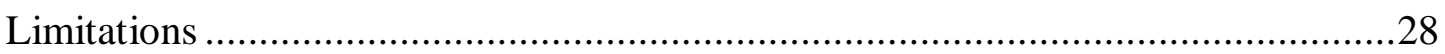

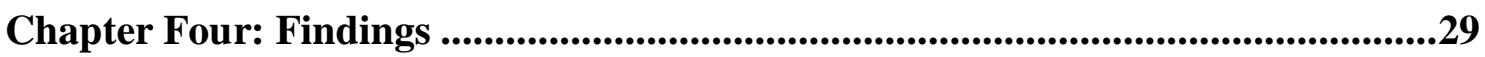

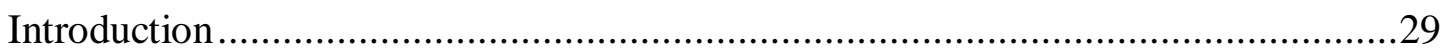

Overview of Participants and Processes ..........................................................29

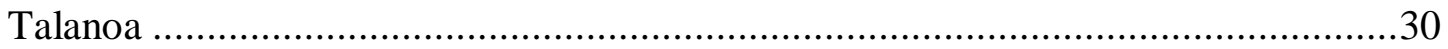

Theme One: Felagolagoma'i (Interdependence) ....................................................

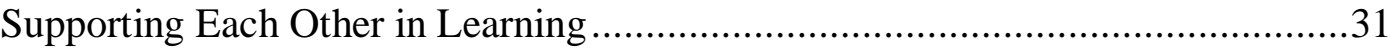

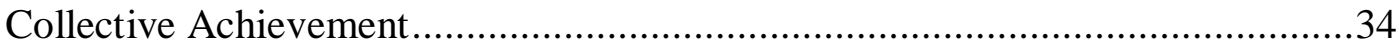

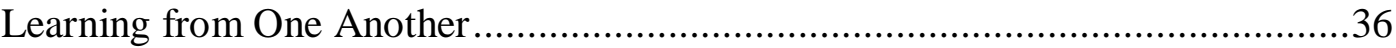

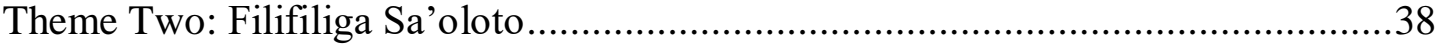

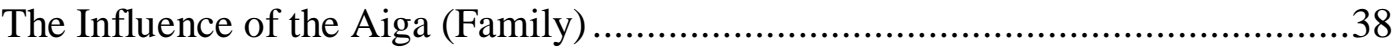

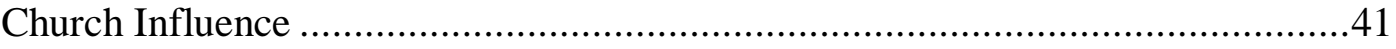

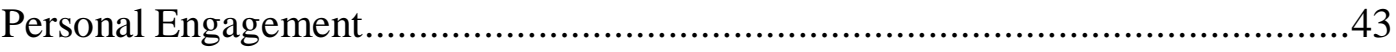

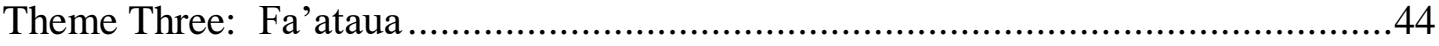

Relationships Between Student and Teacher ...............................................45

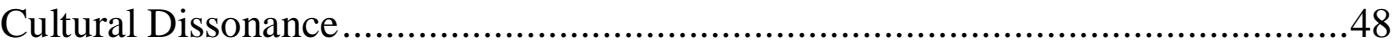

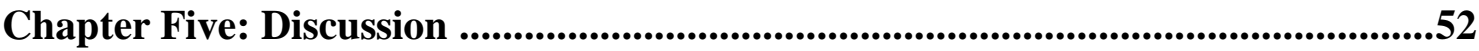

Polycultural Capital in the English Class ...........................................................52

Samoan Students' Perceptions of Strengths and Skills .........................................53

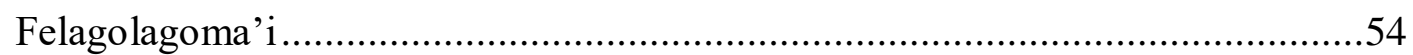

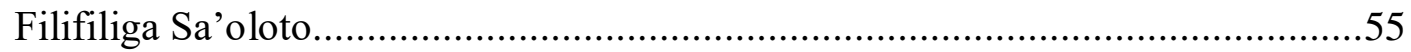

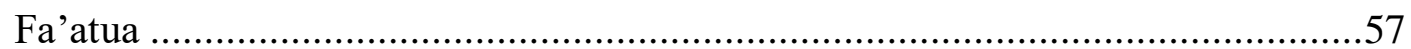

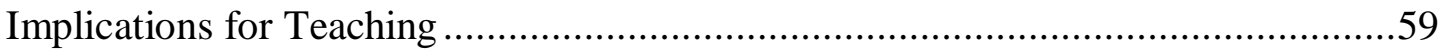

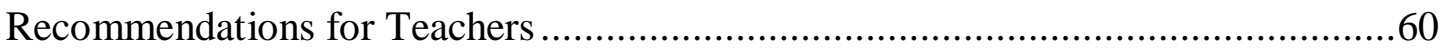

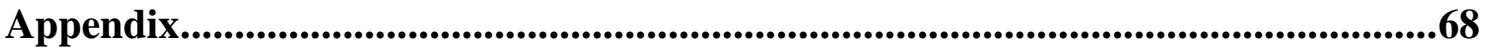

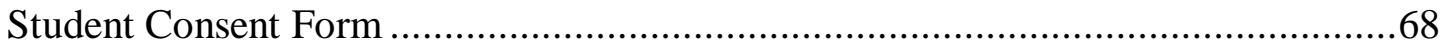

Student Information Sheet - English .......................................................... 70

Student Information Sheet - Samoan........................................................... 72

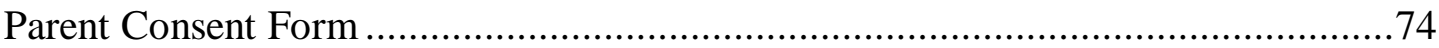

Parent/Caregiver Information Sheet - English .................................................. 75

Parent/Caregiver Information Sheet - Samoan ................................................... 77

Teacher Consent Form.......................................................................................... 79

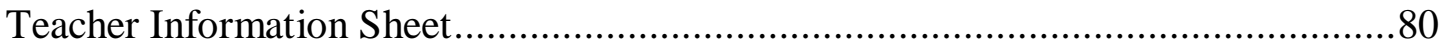

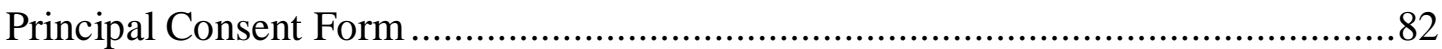

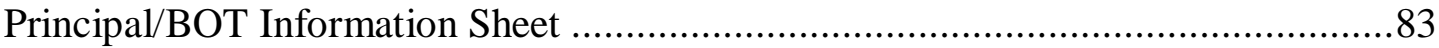




\section{Acknowledgements}

Dedicated in loving memory to my father, Fuataga Kasimani Lautusi.

This thesis was only made possible by the special character of the school involved. For this I am extremely grateful to the incredible principal, the teacher participants who generously allowed me to observe their inspiring practice, and all other staff for being so accommodating and supportive during the data collection phases and afterwards.

I also wish to acknowledge my supervisors, Dr Gillian Hubbard and Dr Cherie $\mathrm{Chu}$, for their guidance and expertise during the research and writing process. I am so thankful for your patience, encouragement and wisdom over the last two years. I definitely would not have considered a Masters if it had not been for both of you.

To my mother Jennifer Cooper, thank you for convincing me I could walk in two worlds, you are my hero. To my oldest brother Kenese Tavita Lautusi, thank you for making sure we remained connected to Samoa, I am such a lucky sister. Thank you so much to my sister Taueu Kasimani-Laumea for all your invaluable guidance and generous help. To all my other brothers and sisters - Kaino Fuataga Kasimani, Fritz Fuataga Kasimani, Zoe Fuatanga Kasimani, Alesana Laumea, Tara Fritz Lautusi and Renee Graham, thank you for all your help and support - I love you. Thank you also to my aunties and uncles in Samoa and New Zealand. I also wish to thank my constants, Julia Croft, Hollie Smith, Adrienne Marsh, Johnny Lawrence, Ruth McIntyre, Shiro Nippert, Cornelios Floratos and all my friends and family for everything you have done in the past year to make sure this thesis was completed. And to Nick van der Veen, thank you for everything you do, I am so grateful for you.

Finally my thanks go to the students of the college, and in particular the participants. I was so humbled by the talanoa and how beautifully led through their worlds I was. For the Samoan students in our education system - may our ceiling be your floor. 


\section{Glossary}

Alofa Samoan word for love and understanding

Afakasi Derived from the word "half caste" and meaning blended cultures of Samoan and Palagi

Aiga Samoan word meaning family

Fa'asamoa The Samoan way of life

Fa'atua To regard others with importance, to be accepting of others opinions and the value of positive relationships

Felagolagoma'i Working with, working for and working interdependently

Filifiliga sa'oloto The concept of having the freedom of your own opinions without fear or pressure from others

Pasifika/Pacific Used to refer to peoples of indigenous Pacific island heritage

Pākehā Māori term describing non-indigenous New Zealanders, often of European decent.

Palagi Used broadly in Samoan to describe white people of European ancestry

Polycultural Karlo Mila's description of the ability of second generation Pacific peoples to accumulate culturally diverse symbolic resources and use them in contextually specific advantageous ways (Mila-Schaaf, 2011)

Talanoa A Pacific research methodology involving open ended conversation (Vaioleti, 2006)

Teu le va To cherish, nurse or take care of the space between things (Samu, 2006)

Whakatauki Māori proverb 


\section{Chapter One: Introduction}

This thesis explores the experiences of 12 Samoan students and how they navigate teaching and learning in a mainstream English classroom. My study is intended to increase teachers' and policy makers' understanding of how Samoan students perceive their own strengths and skills in this English context.

This chapter provides an overview of the study. The first section provides my reflections as a Samoan secondary school student and later teacher of Samoan secondary students. Section Two gives an explanation for my choice of the term 'Pacific' as opposed to Pasifika. I then introduce Karlo Mila's (2010) concept of polycultural capital using a positive deviance approach, and how this was applied as a framework for this study. An explanation of positive deviance in the health sector and the differences between positive deviance and a strengths-based approach is provided. Sections four and five outline the aim of the study and the significance of the topic and, finally, I provide an overview of the chapters in the thesis.

\section{Personal Reflections on Learning and Teaching as a Samoan}

One motivation for this thesis was my own experience of English in secondary school. As a half Samoan and half Palagi who grew up in a Pākehā/Palagi neighbourhood in Christchurch New Zealand, my lasting memory of secondary school is wanting to blend into the background and being constantly afraid I would be asked to provide a "brown" perspective on texts we were studying by well-intentioned teachers, or being singled out as a Samoan success story.

Overwhelmingly I felt teachers were impressed I had broken their stereotyped understanding of what a Samoan student was. Not one teacher knew that both my parents had university degrees. My Samoan father had gained a Bachelor of Science by the age of 25 and my mother a Bachelor of Arts in History and a Diploma in Visual Communications. My teachers also did not know that two of my grandparents were well respected educators and my mother had taught science for several years in Samoa. I clearly remember my mother recalling a time when the principal visited our home and remarked that it was "so nice to see Samoan children coming from a nice household". My mother was infuriated, but this anecdote was just one example of the stereotyped view that Samoans came from 'bad' households and were low achievers which was prominent at my secondary school. 
When I decided to become a teacher in a school with a large Pacific student population I spoke to Samoan students who were still struggling with similar reactions from some staff. I had one conversation with a Samoan student who told me they had been placed in academic classes (an equivalent of 'top stream' classes) and had been questioned about whether they were in the right place when they arrived in class. Despite working with a large number of dedicated and passionate teachers, I was aware of a feeling from some Samoan students that teachers' assumptions stood in the students' way. I have heard many students in my five years teaching express frustration over being unable to work collaboratively with each other, and how counter intuitive it felt not to be able to share knowledge with each other in class. Conversely to this, I saw Samoan students excelling in some classes and I became interested in the skills and strengths the students already had, and what happened when they were provided the space to use these skills.

During the research process and in keeping with the Pacific research methodology of talanoa/discussion (explained in detail in the methodology chapter) the participants and I often discussed my experiences of secondary school. The participants were able to articulate the similarities between my experiences and their own, but they were also quick to point out differences. One of the differences between the participants' experiences and mine that particularly struck me was that these students felt comfortable and confident accessing skills they felt they had learned through the Samoan culture (such as feeling confident learning a speech by repeating it over and over as they had done in church) and my own experience of wanting to hide any part of myself I thought was not 'Western' enough.

During my Honour's year at university and through the professional development programme at my school I found that much of the literature on Pacific learners privileged the opinions of teachers, such as teachers' frustrations with Pacific students who did not ask questions and were reluctant to participate in discussions in class, and the seeming unwillingness of students' parents to engage in their students' schooling beyond conversations about behaviour. The general trends of what teachers reported in the literature were consistent; the recommendations they provided for supporting Pacific learners were strategies such as the use of group work, positive teacher-student relationships, and the use of students' prior knowledge. Yet these recommendations were often general in nature, and lacked specific detail. I was interested in examining existing student skills and their awareness of them more closely, and from the perspective of the 
students themselves. While I had numerous informal conversations with teachers throughout the research process, I purposefully did not include their opinions in the data as a way to ground all findings in the students' experiences. As I am an English teacher the site for this investigation was the English classroom and English curriculum.

\section{Use of the Term Pacific}

Throughout this thesis when referring to people of Pacific cultural heritage I use the term 'Pacific' as opposed to other popular terms such as Pasifika or Pacific Islanders, unless citing a report or article where these terms were used. The term Pacific Islander excludes countries in the Pacific region that are not islands, for example The Marshall Islands (Chu, 2009). The choice not to use the term 'Pacific Islanders' is also an acknowledgement that many people of Pacific descent are no longer living in their traditional island homelands. The use of Pacific and Pasifika is dependent on writers' and researchers' preference. For the purposes of this study I have used 'Pacific' because it is a term that has wide acceptance among the ethnicities that comprise it and does not exclude people of Pacific heritage who live in New Zealand, nor Pacific people from mainland countries and atolls. Samu explains Pasifika is the term used by education institutions because Pacific translates into Pasifika in several Pacific languages (Samu, 2006) but sees the transliteration as lacking depth and meaning. Translating a European word into a Pacific language as a way to "define ourselves" can be seen as itself a metaphor for the way the New Zealand education system views Pacific learners.

\section{Polycultural Capital}

During the research process I was increasingly drawn to Mila-Schaaf's concept of 'polycultural capital' (Mila-Schaaf, 2010) as an explanation for what the participants were saying about the skills they already had that could be transferred into the English classroom to achieve positive learning outcomes. Applied in the health context as part of her $\mathrm{PhD}$ in sociology, Mila used the concept of polycultural capital to "seek alternative ways of theorizing and conceptualizing how the Pasifika second generation operates and identifies culturally" (2010, p. 34). In my study, four of the 14 original participants were born in Samoa but because all the participants verbalised the feeling that they had "come of age" in New Zealand, and had experienced as much if not more schooling within a Western education system, it seemed appropriate to also see my cohort through the lens of second generation. Using polycultural capital, Mila argues against the existing stories that tell solely of marginalisation and cultural loss, which in the health context of her study correspond with addiction and criminality. I saw the value of adapting Mila's 
concept of polycultural capital to the education sector in order to add to a counternarrative to the way national data on Pacific students currently paints a picture of underachievement in the Programme for International Student Assessment reading statistics, National Certificate of Educational Achievement Levels 1, 2 and 3 completion rates, and University Entrance.

Throughout the data analysis process the paradigm of polycultural capital acted as a theoretical construct to interpret and understand the students' reported and observed experiences of the English classroom.

Adapted by Mila from Bourdieu's theory of social space (Bourdieu, 2007), polycultural capital describes the potential advantage the Pacific second generation (New Zealand born) may experience from ongoing exposure to culturally distinctive social spaces (Mila-Schaaf, 2011). Her research took a strengths-based approach, focusing on learning from positive outcomes already achieved within the Pacific population. Mila described her decision to use a strengths-based approach as seeking to learn from achievement and success, rather than failure. Mila argued strengths-based research has a consistency with a positive deviance approach, which recognises that solutions to problems already exist within communities. Berggren and Wray describe positive deviance in the health sector through the example of families whose children's nutritional status deviated positively from the norm (2002). The first appearance of a positive deviance approach in a scientific journal was in Tropical Paediatrics (1972), when Dr Wray asked the scientific community 'What can we learn from successful mothers?' Wray observed that nutritional surveys often discovered that in areas of poverty there existed well-nourished children and pointed out that the local, successful practices the mothers of these well-nourished children used needed to be taught to other poor mothers. The concept of using locally available, sustainable and transferable approaches to improve health has been successfully used to improve the nutritional status of children in several settings for the past three decades (Marsh, Schroeder, Dearden, Sternin, \& Sternin, 2004).

While a strengths-based approach when applied to youth research emphasises how young people are trying their best with the resources at their disposal, positive deviance goes further, because a 'positive outcome' can be demonstrated. Positive deviance "is the observation that in most settings a few at risk individuals follow uncommon, beneficial practices and consequently experience better outcomes than their neighbours that share similar risks" (Marsh et al., 2004, p. 1177). 
The context of my study was government reports that describe Pacific students' failure to engage in school as an explanation for disproportionate numbers of Pacific students leaving school with lower qualifications than their European/New Zealand peers. It was clear to me that my students were engaging in a positive way in the English classes I observed. I needed a tool that would allow me to demonstrate that their behaviours were positively deviant. For this I used a tool with which I was already familiar in my school context. This was Tātaiako: Cultural Competencies for Teachers of Māori Learners (Ministry of Education, 2011) which was designed to provide teachers of Māori students with support to personalise learning for and with Māori to ensure they enjoy educational success. The document provides, among other things, behavioural indicators and examples of learner voice that can be used as a guideline for recognising positive approaches to learning. Although Māori and Pacific learners are by no means interchangable, and have a distinct world-view and preferred teaching practices, there are similarities in how they have reported engaging in the education system. Tãtaiako stresses the need to acknowledge what the learner brings with them into class, the importance of family engagement, respectful relationships, and providing contexts for the learners where their own language, identity and culture are affirmed. All of these are also reported as neccessary to engage and improve learning outcomes for Pacific students. As there is no similar set of indicators for Pacific student success, this document was used as a guideline as one method for viewing successful outcomes.

I was aware that Samoan students at the school I was employed at often were very successful in some spaces, and yet in other areas, were not experiencing the same success. In one class they could articulate what they were learning and why, and in the next they would report sitting at the back and very rarely contributing, or feeling as if what they were learning was not of any use. Using polycultural capital as a conceptual frame allowed me to examine those elements of success more closely in relation to the English classroom. When applied to education, the concept of polycultural capital allows educators to recognise that solutions to problems, such as attendance, engagement or achievement, already exist within the communities, and then to identify potential transferable behaviours and enabling factors for Pacific learners.

Polycultural capital "encompasses agency and ability to effectively reference more than one knowledge tradition: to choose selectively or respond effectively dependent on the context and purpose" (Mila-Schaaf, 2010, p. 12). This research attempted to explore how Samoan students were navigating the English classroom using 
multiple forms of knowledge and effectively responding to teaching and learning, drawing from both their Samoan culture and their knowledge of the Western classroom.

\section{Aim of the Research}

The aim of this research was to understand what strategies Year 10 Samoan students were using to successfully navigate the English classroom. By purposefully investigating the experiences of Samoan students using the Pacific research method talanoa, this research seeks to add to the growing body of knowledge around Pacific learners to help teachers and schools understand more clearly how these learners are approaching the requirements of English. The use of talanoa as a research methodology (discussed in more depth in Chapter Three) offered a less structured approach to data collection and provided the students with a more relaxed atmosphere to discuss their opinions with me and the other participants.

It is acknowledged in the Pasifika Education Research Guidelines (Anae, Coxon, Mara, Wendt-Samu, \& Finau, 2001) that there is a need for Pacific research that empowers both the researcher and the researched. By offering a platform to tell their own education story the participants were able to describe the reality of what was happening for them in class in relation to the values and knowledge they held outside of the school setting.

\section{Significance of the Topic}

Despite the development of the Pasifika Education Plan (Ministry of Education, 2006, 2010, 2012a, 2013) and the recommendations provided for schools within the plan, plus the reports to the Ministry of Education on the progress of Pacific learners (Anae, Mila-Schaaf, Coxon, Mara, \& Sanga, 2010; Ministry of Education, 2009, 2012b; Robinson et al., 2004) and the large scale literature reviews on the research around Pacific learners (Alton-Lee, 2003; Ferguson, Gorinski, Samu, \& Mara, 2008; Gorinski \& Fraser, 2006), there remain large gaps between Pacific students and their New Zealand/European peers. A report by the Education Review Office in 2012 noted that even amongst the schools that were deemed to be most effective in engaging Pacific learners, less than half reported to their Board of Trustees on Pacific students' achievement and none conducted an analysis for effective practice with Pacific students (ERO, 2012). Few of the schools judged as 'most effective' were aware of the Pasifika Education Plan (ERO, 2012). There is no real government requirement that the PEP be implemented in schools, and there is little guidance or support for schools to do so. By looking at the specific details of how 
Samoan students are navigating English, this research could contribute to building teachers' Pacific capabilities and understanding of what successful Pacific students are already doing and how teachers can provide more space for these strategies to be used in class.

The rapidly growing population of Pacific peoples in New Zealand means there is an urgent need to build teachers' knowledge of what is working for this set of learners. In the most recent census Pacific peoples remained the major ethnic group with the highest proportion of children (aged 0-14). Pacific people are a youthful population which means there is a rapid increase in the number of Pacific learners entering and moving up in the New Zealand education system (Quickstats, 2013).

At all levels of education the Ministry of Education and New Zealand government have articulated raising Pacific achievement as one of its priorities due to this group of learners often being represented in statistics concerning low achievement levels in literacy (Sturrock, 2004). As part of this priority the Ministry of Education has identified significant gaps in research areas involving Pacific learners (Chu, Glasgow, Rimoni, Hodis, \& Meyer, 2013) such as how to access and use good data on student outcomes, culturally appropriate ways of involving Pacific communities and further understanding what contributes to positive literacy and numeracy outcomes. This study aims to add to the understanding of what is working for Pacific learners.

\section{Overview of Thesis Chapters}

The structure of this research thesis is outlined below:

\section{Chapter One: Introduction}

Chapter One introduced my personal connection to the topic of Samoan students in the English classroom, explained my choice of the term Pacific and my framing of the research around Karlo Mila-Schaaf's concept of polycultural capital. The chapter then explained the aim and significance of the study. The central aim is to enhance teachers', schools' and learners' understanding of how Year 10 Samoan students are using already mastered strategies to navigate teaching and learning in the English classroom.

\section{Chapter Two: Literature Review}

Chapter Two reviews the key literature on Pacific learners in the primary and secondary school setting in New Zealand. Starting with government reports and literature reviews conducted in the past two decades the chapter outlines the priority goals and major findings from the Ministry of Education. The next section reviews both the New 
Zealand and international literature on culturally responsive pedagogy and finally discusses the current research on Pacific learners in the area of literacy.

\section{Chapter Three: Methodology}

Chapter Three outlines the research methodology and procedures used in this study. The chapter defines the Pacific methodology of talanoa and why the approach was taken in partnership with a Western methodology; next is an explanation of the participant selection process. There is then a description of the data collection method and data analysis process and the chapter finally considers the ethical considerations and limitations encountered during the research.

\section{Chapter Four: Findings}

Chapter Four discusses the findings from the research. Split into three sections this chapter defines the key themes of felagolagoma' $i$, or - working with, working for and working interdependently, filifiliga sa'oloto - the concept of having the freedom of their own opinions without fear or pressure, and finally fa 'atua, or regarding others with importance, to be accepting of others' opinions and the value of positive relationships.

\section{Chapter Five: Discussion and Recommendations}

In Chapter Five the research findings are summarised in relation to current research and connections are made to Mila-Schaaf's (2010) theoretical construct of polycultural capital. Implications of the study are outlined and recommendations made for stakeholders in Pacific education. 


\section{Chapter Two: Literature Review}

The review will firstly explore the past two decades of reports from government departments on Pacific research, initiatives, education outcomes, and recommendations. It will then look at both international and local research on the use of culturally responsive pedagogy for diverse classrooms. Literature on the English classroom and literacy practices specifically aimed at improving achievement for diverse students are then examined. Lastly, theories on home-school partnership and the implications of making connections between the multiple worlds Pacific students inhabit are explored. As a 90point thesis does not allow for all literature to be included, these texts were chosen as they provide insight into what is happening for Pacific students in class and what the current research is suggesting that positively impacts Pacific students' success in school in general, and also specifically the English classroom.

This chapter focuses on the literature about Pacific peoples' success, and the barriers to success in the New Zealand education system. Within the New Zealand context much of the literature on what is best for Pacific learners is treated as interchangeable with what works best for Māori students (Fletcher, Parkhill, \& Harris, 2011; Hawk, Cowley, Hill, \& Sutherland, 2002; Hill \& Hawk, 1998; Hynds \& McDonald, 2010; McNaughton \& Lai, 2009; Robinson, 2000; 2011). When researching Samoan students, a large amount of literature reviewed is under what Tanya Wendt-Samu refers to as the 'Pacific Umbrella' (Wendt-Samu, 2006).

\section{Government Initiatives, Plans and Policies}

The Pasifika Education Research Literature Review (Coxon, Anae, Mara, WendtSamu, \& Finau, 2002) reported many factors that acted as barriers to Pacific students' success in New Zealand schools.

The factors identified were:

- The impact and consequences of 'Tomorrow's Schools', especially in terms of school choice, de-zoning and school-based governance

- The mismatch of a Western style of school structure and processes with the culture of Pacific learners and their families

- The lack cultural connection between the teacher and learner 
- The absence of Pacific knowledge in the New Zealand curriculum

- Poor community- school relationships.

Although the authors of the 2002 report describe an increase in conference paper presentations and a steadily growing body of Pacific researchers, they point out that most of the research is still produced by a very small group of established Pacific academics. The most recent report to the Ministry of Education in 2013, over a decade later, also described significant gaps in research and the government report suggests very similar research priorities. The significant research gaps and identified research priorities in the 2013 report were outlined as: the need for access to good data on Pacific student performance; research on culturally appropriate ways of involving Pacific communities in governance and leadership and as partners in the educational process at all schooling levels; research on culturally responsive ways to promote positive home-school partnerships and parental engagement in school as well as identifying parental aspirations for their children; and more research regarding culturally responsive approaches to improving literacy and numeracy outcomes for Pacific students and research on transition experiences for Pacific learners to the next level of education.

The vision in the New Zealand Government's most recent Pasifika Education Plan 2013-17 is to "create the conditions for strong, vibrant and successful Pasifika communities - communities that can help build a more productive and competitive economy for all New Zealanders" (Ministry of Education, 2012a, p. 1). However, despite the apparent government focus on improving the educational outcomes of Pacific students for the past two decades, little seems to be improving for these learners. The findings of the third Education Review Office report on how schools engage with Pacific learners highlights the lack of improvement. The Education Review Office report stated that the ways in which schools engaged with Pacific students and families was "disappointingly consistent with those found by the Education Review Office in its 2009 and 2010 national evaluation report" (ERO, 2013). It has been acknowledged in numerous large scale government reports that Pacific learners are not enjoying the same success as their European/New Zealand peers (Alton-Lee, 2003; ERO, 2009, 2010, 2012, 2013; Gorinski \& Fraser, 2006; Ministry of Education, 2006, 2012b, 2013), and more needs to be done in schools to meet the needs of the different Pacific groups. The acknowledgment has not yet translated into a requirement for schools. The need to do something to address the learning outcomes for Pacific students is becoming more urgent due to the rapidly increasing youthful Pacific population (Quickstats, 2013). The need to address the gap in 
positive educational outcomes for Pacific learners is made clear in the most recent report to the Ministry of Education - An analysis of recent Pasifika Education research literature to inform improved outcomes for Pasifika learners (Chu et al., 2013, p. 1) which aims to both "clarify key evidence towards improved learning and achievement for Pasifika learners" and act as a critical analysis of the Pasifika literature since 2001.

The Pasifika Education Plan Monitoring Report (Ministry of Education, 2010) outlines one of the future targets for Pacific students in compulsory schooling as increasing the proportion of Pacific school leavers achieving NCEA Level 1 literacy and numeracy requirements from $84 \%$ in 2008 to $93 \%$ by 2013. The then Minister of Education and Minister of Pacific Affairs set out the following aspiration:

\footnotetext{
Our Government's goal is to create the conditions that grow strong, vibrant, capable Pasifika communities. Participation in quality early childhood education and continued achievement in compulsory education provide critical foundations for Pasifika to achieve good school leaving qualifications, at least NCEA level 2. These will open doors to various tertiary education opportunities and lead to strong employment prospects. (emphasis added) (Ministry of Education, 2010, p. 3)
}

Although the Minister of Education claims no student should leave school without a minimum of Level 2, there is a separate and far lower goal of $93 \%$ of Pacific students to gain a Level 1 qualification.

Three years after the 2010 report, the 2013 Pasifika Education Plan Monitoring Report did not show an increase in the Level 1 desired target of a 93\% pass rate. In regards to Level 2 the document stated: "with the positive increases to date, if this can be continued, Pasifika students are expected to meet the target of $85 \%$ of Pasifika 18 year olds with an NCEA Level 2 qualification or equivalent by 2017" (Ministry of Education, 2013, p. 22). A 2013 Education Review Office report - Making Connections for Pacific Learners' Success - describes the focus on NCEA Level 2 being of particular significance as "it is now seen to be the desired minimum qualification for school leavers giving them opportunities in terms of further education, employment, health outcomes and a better quality of life" (ERO, 2013, p. 4). Yet the goal of $85 \%$ of Pacific learners to achieve Level 2 is laid out as a future goal for 2017, not an immediate goal. Both the 2010 and 2013 Pasifika Education Monitoring Reports outline aspirational goals for Pacific students as lower than the targets they set for all New Zealand students, the goals that are explained as the minimum required to participate fully in the New Zealand economy.

The 2012 Education Review Office report Improving Education Outcomes for Pacific Learners, described the Pasifika Education Plan as having little impact on Pacific 
learners and stated that: "Although ERO found positive practices in some schools, there were no significant system-wide changes evident in the way schools were responding to Pacific students, despite the widely recognised disparities in educational outcomes for these students" (2012, p. 1). In spite of numerous recommendations, reports, identified issues and gaps in research, there is little evidence of substantial changes in the way schools are addressing the recognised barriers for Pacific learners.

\section{Culturally Responsive Pedagogy}

There is a vast body of literature focusing on culturally responsive or culturally relevant pedagogy in both New Zealand and international classrooms. The scope of this 90-point thesis does not allow for the inclusion of all major studies. This chapter will focus primarily on research on using culturally relevant pedagogy in New Zealand secondary and primary contexts to improve the quality of education for Pacific learners.

According to Alton-Lee (2003, p. 4):

The high disparities, the relatively high variance within schools in the New Zealand PISA results, and our rapidly growing demographic profiles for those learners traditionally underserved by New Zealand schooling, indicate a need for community and system development to be more responsive to diverse learners.

The introductory comments in the New Zealand Curriculum (2007) state that "The New Zealand Curriculum is a clear statement of what we deem important in education" (p. 4), and in both its vision statements for young people and its principles the document professes a hope that students can clarify their own identities and heritages and form positive connections to their own identities. In the following section I will discuss current New Zealand research studies that critique how educators, policy providers and stakeholders in Pacific education are attempting to address the high disparities between New Zealand/European students, whose culture dominates the education system, and Pacific students whose culture does not, through acknowledging the need for pedagogies that are culturally relevant to Pacific learners.

Some of the barriers faced by Pacific students in the literature create a mismatch between the value system of the school, governed by the value system of the policies in place that inform school governance and decision making, and their own Pacific cultural values. Spiller's (2012) interpretive case study of Year 9 Pacific students and their teachers found that while teachers are well meaning in their approaches to Pacific students, they are often unable to interpret the students' actions in the way the students may have hoped. In her study of Year 9 Pacific students, Spiller examined the views of 
Pacific students in the Year 9 classroom across science, English, social studies and mathematics, and the assumptions and beliefs of their teachers about these students. Spiller used observations and focus group interviews with Pacific students and their teachers to examine the complexities of teachers' best intentions and the dangers of viewing all Pacific students as a single entity. Spiller observed engagement was linked closely to 'good' and 'poor' behaviour, which in turn was related to behaviours of avoidance (keeping their heads low, covering their work) or appropriate on-task behaviour. She also explained the differences between on-task behaviour and engaged on-task behaviour, where students were not only completing tasks, but were excited and involved in the learning. Teachers explained an awareness of how the students learned best, such as in groups via hands-on or interactive tasks, but often resorted back to a more traditional style of teaching. The beliefs that emerged in the discussions with teachers showed how many assumptions about the Pacific students affected the relationships and levels of engagement and behaviour in class. Often teachers blamed poor behaviour on the students' home life and relationships broke down when teachers' authoritarian actions and words made students feel as if they were being unjustly punished. Another observation was that the often quiet nature of Pacific students' parents caused teachers to lower their expectations of the student. The author suggested that Pacific students will engage more when teachers allow them dignity in their learning.

This happens when the teacher shows them respect as a person, speaks quietly to them, listens attentively to them when they have something they want to say, and responds with respect to their ideas and questions. They also ask that they not be singled out for help. They will ask for help when they need it and they want to be able to ask their friends first (Spiller, 2012).

Siope's (2011) Master's thesis examined the schooling experience of two generations of Pacific students in mainstream schools in New Zealand. Using semistructured interviews with open-ended questions, Siope interviewed two groups of Pacific secondary students from Years 9-13 in two low decile schools, and recalled her own experience of schooling as a Samoan in the 1970s and 80s. She spoke about the 'siloed' worlds of many Pacific students, who often exist in multiple contexts that are kept separate by students. The result of this separation is that Pacific students' school and home life do not have a meaningful connection to each other. Siope, similarly to Spiller, highlighted the importance of relationships with key adults to Pacific learners in order to engage these students: "It was these, responsive, readily accessible, reasonable adults, 
whose collective wisdom recognised and then activated 'our' potential for learning" (Siope, 2011, p. 15).

There is an acknowledgement in the research that for schools to best serve Pacific learners they need to be culturally responsive. There is, however, very little research where researchers continue to track student achievement after the end of an intervention (Lai et al., 2010). Lai, et al. considered whether interventions put in place in decile 1 primary schools to raise achievement levels for Pacific learners were sustainable after funding for an intervention had finished or the professional development block had been completed. Much like the government reports in the last decade, Lai et al. suggested schools need to identify specific student learning needs from the data, introduce ongoing inductions for new staff members into culturally responsive practices and imbed observational tools to provide feedback to the wider staff for long-term, sustainable improvements in learning outcomes for Pacific students.

Hynds and McDonald (2010) investigated teachers' perceptions of the key motivational factors concerning the improvement of teacher practice across the curriculum to improve learning for culturally diverse students. The study was of a qualitative design using semi-structured interviews and questionnaires from a group of 27 elementary and secondary school teachers across nine curriculum areas who had previously participated in The Quality Teaching Research and Development Project. The study aimed to find out what the key motivational factors were for initiating and sustaining their engagement in the initiative. Some challenges teachers in the study found were variations in support from their schools to improve practice, the difficulty in bridging the gap between theory and practice, and difficulties in engaging students. A key motivating factor for teachers was the appeal to the teachers' sense of social justice; teachers reported being aware of the disparity in achievement and the potential for improved outcomes for Māori and Pacific students. Teachers in the study were also motivated to participate in the hope that it would improve their practice and make teaching a more satisfying experience with diverse students. Many teachers also reported the new knowledge they gained about culturally responsive teaching altered their practices and improved student outcomes in their classes.

Allen, Taleni, and Robertson (2009) also investigated teacher practice in regards to developing an appreciation of the challenges Pacific students face in coping with an education system based on cultural values that are not theirs. Using semi-structured focus groups supported by personal journals, the researchers sought to understand how a trip to 
Samoa may change teachers' thinking in relation to Pacific learners. Although the replication of the study, which focused on the insights of five teachers (from both primary and secondary school), would be difficult as it may not be cost effective for most schools' professional learning programme, the experiences changed the thinking, relationships with Pacific students and the community, and the classroom practice of the teachers. The teachers changed classroom practices after their trip to Samoa; the changes included making instructions very clear for second language learners, facilitating transitions between tasks through the use of music and village type activities, using more structured, formal oracy, and acknowledging Pacific students needed to work together as well as individually. Strengthening relationships with students came through strengthening the teachers' own cultural self-efficacy. Gaining an understanding of Samoan culture through cultural immersion allowed teachers an opportunity to examine and transform their cultural assumptions, attitudes and beliefs.

Teachers' assumptions about both Pacific students and Pacific parents was discussed as a major barrier to developing positive relationships by Nakhid's (2003) empirical study using a mediated dialogue methodology. The study sought to investigate the accuracy of the perceptions a group of six students and five teachers held of each other. Nakhid found one explanation for schools that failed to address the lower academic achievement of Pacific students was the perceptions teachers had of their Pacific students. The teachers involved in the study reported they often did not see the Pacific students as working to their ability or motivated to learn, and attributed the students' lack of achievement to cultural factors such as home expectations. The teachers in the study also stereotyped the parents' role in their children's education, and the limited knowledge of the parents ensured these mostly inaccurate beliefs remained in place throughout the interview process. Fletcher, Parkhill, Fa'afoi, Taleni, and O'Regan (2009) similarly investigated pedagogical factors and family/community factors that influence literacy learning outcomes for Pacific students in primary school. Again, the focus of the study was on the teachers' and parents' perceptions of what provides supports and barriers for these students. Using the Pacific research methodology of talanoa the authors discussed various issues with two groups of teachers, Senior Leadership Team members and specialist reading teachers from a cluster of five schools. The purpose of the talanoa was to identify participants' perceptions of factors and barriers that impact on Pacific student learning. Many of the reasons teachers identified placed the blame at the foot of the learner and the aiga. Teachers gave examples such as a lack of appropriate reading material at home, a lack of comprehension of texts due to limited vocabulary, students 
being unwilling to take risks in class and limited parental interest in the life of the child in school. The teachers also commented that students' unwillingness to question the authority of the Bible translated into being unwilling to question authority in general.

Culturally responsive pedagogy is not a new concept. Internationally, Gay (2002) argues for the inclusion of culturally relevant pedagogy to improve the school success of ethnically diverse students, and these international studies offer important considerations for the New Zealand schooling system. Gay defines culturally responsive teaching as "using the cultural characteristics, experiences, and perspectives of ethnically diverse students as conduits for teaching them more effectively" (2002, p. 105). Gay points out the importance of situating academic skills within the lived experience and frames of reference of the learners, making these experiences more meaningful and allowing a personal connection. Further, Banks, et al. (2001) call for professional development programmes in schools to take responsibility for helping teachers understand the complex characteristics of different ethnic groups. The authors argue that teaching programmes should allow for all students to have equitable opportunities to learn and meet high standards, not only the students whose own culture resembles the culture of the education system most closely, and, that the curriculum should help students understand that knowledge is socially constructed and have an understanding of whose view point is privileged and allow opportunities to question these. Sleeter, in an article arguing the importance of strengthening culturally responsive pedagogy (2011), warns that culturally relevant pedagogy is often understood in limited and simplistic ways, giving the illusion of having made meaningful change without any actually happening. She gives examples of culturally responsive pedagogy being trivialised both internationally and within a New Zealand context as purely being a 'cultural celebration' with little knowledge informing the teachers' views of students' culture. This kind of approach essentialises cultures to stereotypes and assumptions that working with culture or acknowledging differences within class will solve problems of equity. In a review of literature on culturally responsive pedagogy for indigenous youth in America, Brayboy and Castagno (2008) also highlight the issue that while there is a plethora of writing on culturally responsive pedagogy, it has little impact on what teachers do because it is "too easily reduced to essentialisations, meaningless generalisations or trivial anecdotes - none of which result in systematic, institutional, or lasting changes to schools" (p. 941). 


\section{Literacy and Identity}

This section will discuss the literature on Pacific learners' in-school and out-ofschool literacies and the complexities of literacy programmes in multicultural classrooms. The essence statement of the New Zealand Curriculum (Ministry of Education, 2007, p. 18) states that: "Literacy in English gives students access to the understanding, knowledge, and skills they need to participate fully in the social, cultural, political, and economic life of New Zealand and the wider world". The importance for students to appreciate and enjoy texts in all their forms and understand how language works is established as fundamental to students' success across the curriculum in this essence statement. The importance of teachers' knowledge of their students' background experiences and home literacy practices is recognised as a key to this success in other Ministry documents. In Effective Literacy Strategies in Years 9-13, the authors state:

Teachers who knew about their students' backgrounds can develop a classroom community of learners who view diversity as an asset and are aware of its potential for enriching the learning of both teacher and student. (Ministry of Education, 2007, p. 7)

The key readings on Pacific learner literacy encountered during this review process have also been usefully collected in a 2013 article by Kerensa Robertson (2013). Robertson comments on the significant amount of research that has been undertaken on Pacific learner education since the 2000 Programme for International Student Assessment report on Pasifika Education (Sturrock, 2004). Robertson highlights some of the key findings in the research she assembled since the PISA report. The key findings were: the need for teachers to recognise a large number of Pacific language learners as second language learners and have an awareness of the implications of this; the need for schools to strengthen the connection between the homes of the students and the school; a need for the recognition that students are often crossing from one 'world' to another; the need to build on the strengths of Pacific learning by utilising the often strong connections to the Bible; and providing students with the opportunity to use their own experiences to make meaning from texts studied in class. The article concludes with a statement I found to be very true during my own review process:

Understanding students' existing strengths in out-of-school literacies and using their experience of other worlds is of use. Nevertheless, to benefit Pasifika students in literacy learning there is a void in pragmatic advice for the teachers, and this advice needs to be further developed. In particular there is also limited research available for secondary teachers that have practical and implementable strategies and ideas. (Robertson, 2013, p. 44) 
A recent New Zealand research study by Edwards (2014) investigated 18 mainstream secondary school teachers' knowledge of second language acquisition and their knowledge and use of teaching resources and strategies for supporting English Language Learners (ELLs) in the mainstream classroom through an online questionnaire. The findings from this study indicated that only a small portion of teachers surveyed online were confident in their knowledge of the nature of second language acquisition (17\%) and that most teachers who participated had very little knowledge of the resources available to them. Only five of the 18 participants had used any of the resources available through the Ministry of Education, despite the most recently developed English Language Learning Progressions (ELLP) document having been available in schools for at least two years prior to the survey. In order for the high number of Pacific learners who are second language learners to have a greater chance of developing academic language, mainstream teachers must improve their knowledge of how to scaffold learning and what resources are available to improve practice.

In the primary school context Dickie's (2011) ethnographic case study investigated 14 Samoan students' out-of-school literacies with data gathered from photographs, journals and interviews, including interviews with three adult representatives from the church associated with the students. Using Rogoff's three planes of analysis Dickie examined the students' practices at a personal, interpersonal and community level to offer the students' own perspectives of areas of conflict. He found the areas of contradictory values for the students' construction of literacy included cultural and social perspectives on popular culture. Samoan students encountered a conflict in values related to swearing and images of violence in computer games and popular music on the one hand and the values of family, church and school on the other hand. There were also conflicting perspectives about whether the students should maintain their mother tongue or adopt the dominant language of the society around them. The students expressed an understanding of the importance of maintaining their Samoan language and valuing the connection it provided with older family members and their culture, yet also described feeling ashamed to speak Samoan at school. Dickie highlighted the need for teachers to understand that Samoan students constantly have to negotiate one set of values for another, and between the sites of school, church and home these are often contradicting values. He points out that one implication for literacy is that it would be useful for teachers to be aware of this and use the strengths that come from different sites, such as religious literacy patterns, and incorporate these into school literacy. 
When students face conflicting values among their sites for literacy, these may provide useful links for teachers. Incorporating out-of-school literacies to enhance literacy in the classroom represents a challenge for teacher professional judgment and curricular adaption.

Interviews with the three adults connected to the church in Dickie's study revealed that the students were well versed in comprehension of passages from the Bible, and placed a high value on understanding both the implicit and explicit meanings that the passages held, then relating this to their own lives. This is a transferrable skill that teachers may not know the students have.

In a primary school based study, Fletcher, Parkhill, Fa'afoi, and Taleni (2008) investigated Pacific students' perspectives on the literacy practices that were effective and less effective during their primary schooling. Data were collected in two phases through focus groups and open-ended interviews. Phase one involved two primary schools and phase two, four primary schools, all in Christchurch and ranging from deciles $1-5$. In both phases all students in the schools plus one or more teachers were present during the interviews; in two schools the principals also attended. The researchers reported reluctance in the first session from the students to contribute, yet with encouragement they became increasingly confident. Questions were asked such as "What helped you to become readers and writers?" and "Where did you get your ideas for writing from?" The findings in both phases indicated that Pacific students felt more secure and confident when the practices of the classroom acknowledged their own cultures and there was an opportunity to make connections between their home life and school life. The researchers urged schools to seek positive partnerships between home and school to improve the acquisition of students' literacy skills (Fletcher et al., 2008).

A synthesis of findings from the New Zealand research studies by Fletcher, Parkhill and Harris reported that learning is facilitated by the establishment of positive relationships with teachers for Pacific students and Māori students, and that collaboration and co-operation within small groups supported learning for these students (Fletcher et al., 2011). Fletcher et al. note that although developing positive relationships and the use of small group work may appear a simple way of positively supporting learning or Pacific and Māori learners, putting them in place may require school-wide support. 


\section{Chapter Three: Methodology}

\section{Introduction}

In this chapter the research methodology and procedures are outlined. The chapter starts with the research questions used to guide the study, followed by an explanation of the Pacific research methodology talanoa in partnership with a Western framework; next is an explanation of the participant selection process. It will then describe the data collection method and data analysis process and finally consider the ethical considerations and limitations encountered during this research.

\section{Research Questions}

The central questions for this study are:

What perceptions does a group of Samoan students have of the strengths and skills they bring to the English classroom?

How do these students see themselves as navigating teaching and learning in the English classroom drawing on these strengths?

\section{Negotiating Western and Pacific Methodologies}

Much of the research that has had Pacific peoples at its centre has been described as at best of no benefit to Pacific peoples and at worst "actively dis-empowering" to the participants and communities involved in research studies (Anae et al., 2001, p. 20). When undergoing research on Pacific issues and involving Pacific participants, Pacific researchers are faced with the question: How, while still valuing our own ways of knowing, can research be in a partnership with Western methodologies? As a developing Pacific researcher I was conscious of this question.

Suaalii-Sauni and Fulu-Aiolupotea (2014) describe Pacific junior researchers benefiting most when there is deliberate and mutual sharing and probing of Pacific and Western epistemologies inherent in contemporary Pacific research. Suaalii-Sauni and Fulu-Aiolupotea call for:

the deliberate pursuit of an enabling two-way conversation between researchers and between researchers and participants, a conversation that privileges a research process that always keeps at the forefront a respect for cultural context and meaning, no matter what the research $(2014$, p. 336).

One way I attempted to acknowledge Samoan ways of knowing, while also using Western research methodologies, was to acknowledge the use of a Western qualitative 
phenomenological approach and place it in partnership with both talanoa, which is described by Vaioleti (2006) as a "personal encounter where people story their issues, their realities and aspirations"(p.22), and Teu le va, a Samoan system for negotiating and understanding relationships as philosophical and methodological approaches as other researchers have done.

\section{The Western Framework}

Seen from a Western perspective the following research uses a phenomenological qualitative approach, which was used in order to gain an in-depth knowledge of the participants' experiences in the English classroom, to gain insight into the cultural values and practices they employ to help navigate the demands of the English classroom. The qualitative data collected were taken from the participants' 'lived-realities' and provided a thick description of how the students experienced success and barriers in English in their own voices (Creswell, 2003). A case study structure was selected to allow for an in-depth understanding of a specific case within real life. A case study allows the researcher to illustrate an issue, and compile a detailed description of the setting for the case. Yin (1984) defines the characteristics of a case study as "investigating a contemporary phenomenon within its real-life context, especially when the boundaries between the phenomenon and context are not clearly evident. In this way it is an empirical inquiry which seeks to understand the complexities of a situation or phenomenon in a 'real life' context." (p.23)

Specifically, this study adopted a phenomenological approach where the researcher investigates a phenomenon (a reality or experience) that can be described by the participants as they 'live' the experience. It is the participants' exact words that are the focus of the data collection. Johnson and Christensen describe the potential phenomenological research as a way to understand an individual's or group's life-worlds and how they ascribe personal meaning to a specific phenomenon. They also argue the importance in 'bracketing away' any preconceptions the researcher may have about the phenomenon in order to experience the phenomenon 'as it is' (Johnson \& Christensen, 2012).

The theoretical basis of this study is within an interpretive paradigm. Following Klein and Myers (1999), the foundation assumption for interpretive research is that knowledge is gained, or at least filtered, through social constructions such as language, consciousness, and shared meanings. In addition to the emphasis on the socially constructed nature of reality, interpretive research acknowledges the intimate relationship 
between the researcher and what is being explored, and the situational constraints shaping this process (Rowlands, 2005). The interpretivist paradigm is concerned with understanding the world as it is - to understand the fundamental nature of the social world, at the level of subjective experienced. Finding its beginnings in the tradition of Kant, the interpretivist paradigm seeks to understand issues relating to the nature of the status quo, social order, social integration and cohesion, solidarity and actuality (Burrell \& Morgan, 1979).

\section{Talanoa}

This research study has been guided by The Pasifika Research Guidelines. The authors of The Pasifika Research Guidelines (2001) explain that the role of Pacific research is:

...primarily not only to identify and promote a Pacific world-view, which should begin by identifying Pacific values, and the way in which Pacific societies create meaning, structure and construct reality, but complementary to these is a need to also interrogate the assumptions that underpin Western structures and institutions that we as Pacific peoples have adopted without much questioning. (Anae et al., 2001, p. 7).

One way of exploring the participants' world-view and values in a way that was empowering, was through the use of talanoa. The most literal translation of the term talanoa is 'tala' meaning 'to inform, tell, relate and command, as well as to ask or apply' and 'noa' meaning 'of any kind, ordinary, nothing in particular, purely imaginary or void" (Vaioleti, 2006, p. 23)

Tongan academic Timote Vaioleti, mostly cited as the original articulator of the talanoa research methodology, has described typical Western data collection methods as not requiring a personal relationship between the researched and the researcher. When considering epistemology he explains the dangers in "assuming that all Western, Eastern and Pacific knowledge have the same origins and construction, so that, by implication, the same instruments may be used for collecting and analysing data and constructing new knowledge" (2006, p. 22). Disempowering research, which has led to no real improvement in Pacific peoples' economic or social position in New Zealand, has a historical pattern of collecting participants' stories and retelling them through their own non-Pacific world view. Smith (2012) critiques the positivist tradition (a philosophical system which recognises only that which can be scientifically verified, or has mathematical proof) and describes that what counts as Western has expanded far beyond the boundaries of Western science and 
penetrates every part of the rules and value systems that govern how both indigenous and Pacific peoples operate in New Zealand society.

In designing a methodology to gather the voices of my participants, and explore the strengths and skills that they use to navigate the English subject it was imperative to acknowledge the historical implications of this type of research on Pacific peoples. Vaioleti recognises a shift in the use of traditional research approaches, and increasing acceptance and space for Pacific research methods such as talanoa. Although talanoa can sit within a similar family to qualitative methods such as an open-ended or informal interview, the approach differs due to the personal way in which the encounter needs to happen. Talanoa is described by Vaioleti as "a conversation, a talk, an exchange of ideas or thinking, whether formal or informal" (p. 23); it is almost always carried out face to face, Farrelly and Nabobo-baba (2014) argue for the merits of talanoa being "an empathetic apprenticeship", used "to enhance shared understandings between all human beings and is essential if talanoa is intended as a decolonising research methodology" (p.319). Farrelly and Nabobo-baba highlight the dangers of employing talanoa as a culturally responsive method while treating it as interchangeable with informal openended interviews. They emphasise that valid talanoa is a culturally and emotionally embedded reciprocal exchange between researcher and participants.

In order to empower my participants and their stories it was important to recognise the context in which the talanoa took place, to build on the relationship and alofa (love) we created throughout the year. I also shared my own hopes, fears, aspirations and experiences with them - this reciprocity encouraged them to trust I was using their talk as the gift it was, strengthened by the sharing of prayer and food. Talanoa in this way is far more than an informal interview or simple culturally responsive data collection method. Farrelly and Nabobo-baba articulated what was my experience during the research well - "we hold our participants in our hearts and within our bodies for a long time after our fieldwork: we bear emotional and physical scars and share physically and emotionally in our participants' hopes, dreams and moments of joy.” (2012, p.4)

Both Ministry of Education reports - Teu Le Va (Anae et al., 2010) and The Pasifika Research Guidelines (Anae et al., 2001) - suggest the need for research that resists treating 'Pasifika' as a homogenous group, and to recognise and value the cultural complexities which Anae et al. describe as not only the multi-ethnic nature of Pacific communities, but also the intra-ethnic nuances of the diverse groupings and identities of Pacific peoples in New Zealand. This is important as although my research is ethnic-specific - the participants 
all identified themselves as Samoan, there were many complexities within the group, and these needed to be recognised and valued to prevent what Anae et al. identify as a glossing over and ignoring of important cultural complexities.

\section{Teu le va: Negotiating the Relationships}

Talanoa can only offer empowerment to participants of research if there is a genuine and reciprocally respectful relationship between researchers and the researched. The significance of mutually respectful and caring relationships in Pacific research is also emphasised in the Samoan cultural reference of 'teu le va' - explained by Melani Anae (2010) as a Pacific indigenous methodology for directive action in negotiating research relationships, as "a philosophical and methodological turning point in education praxis" (p.12). Teu le va focuses on the centrality of reciprocal relationships, based on the Samoan concept of teu le va.

During the research process I became increasingly drawn to teu le va as a way to navigate the relationship between myself, the participants, aiga, teachers and other stakeholders in Samoan education and keep that question of how the research I was conducting could benefit the research at the centre of my decisions.

The concept of teu le va as a philosophical underpinning also spoke to the strength-based approach of the research - exploring the strengths the participants had already mastered, and how transferrable these are into other spaces. A strengths-based approach to research recognises the resilience and resourcefulness in all participants and actively rejects deficit thinking. Teu le va emphasises working together and sharing power - it is described as signalling a "move away from a focus on failure, 'the tail' of underachievement, and deficit, to a focus on potential and on everyone in the education system taking responsibility for optimising education outcomes for and with Pasifika learners" (Arini, et al., 2010, p.5).

\section{Research Design}

\section{The Setting}

The research took place in one decile two state co-educational urban secondary school in a large New Zealand city, with a roll of approximately 780 students. It is an ethnically diverse school. The Pacific population at the time of the research was $36 \%$ of the school roll and of this population $85 \%$ identified as Samoan. The talanoa were all conducted in an informal setting in a private room used by the specialist classroom teacher, but vacated for the months when the talanoa was taking place. 


\section{The Participants}

The original participants of this study were 14 Year 10 Samoan students in two separate English classes at the college. However, during the research process two students left the school. The two participants were not included in the findings of this study as they left before initial talanoa took place. The remaining participants all identified on the school roll with Samoan as their 'primary ethnicity'. Purposeful sampling was used to select the two classes that would participate in this study (out of 6 Year 10 classes at the college). The two classes were selected for two reasons, firstly they both had the highest number of Samoan students (8 in one class and 6 in another class) and secondly as the college is my site of employment I had observed a range of culturally responsive teaching from the English teachers of these classes, and was interested to see how the participants responded to the wide range of strategies.

The 12 students who participated in the talanoa had many similarities and differences, and, for the purpose of understanding some of the intra-ethnic complexities these can be broken down into the following information:

- 10 boys and 2 girls

- 10 identified as speaking fluent Samoan

- 8 were New Zealand born

- 2 had arrived within the last 5 years

- 2 had arrived over 10 years ago

- 10 participants' parents spoke Samoan as a first language

- 2 students were half Samoan and half Māori.

\section{Data Collection}

Participants were divided into four groups, each with three participants (after two participants left the school). Data were collected through initial talanoa and audio recorded on my phone. All participants signed consent for this prior to the initial talanoa. The next stage was an observation of the English class which was recorded through handwritten notes. In the week following the classroom observation the participants and I had a follow-up talanoa, focusing on my observations from the English class. A second classroom observation was conducted two months after, and again there was a follow-up talanoa in the same groups of three. All talanoa were audio-recorded on my phone. 


\section{Contact with Parents}

Before talking to the students, I contacted all parents by phone. I had previously met four participants' aiga during the previous year at rugby games and one participant's aunty as I had taught an older sibling. I called these families first and explained the purpose of the research and the involvement of the students. After assessing how these conversations went I called the rest of the families. All caregivers at this point were willing for their child to participate. Following this I sent an information letter home outlining what we spoke about in the telephone conversation. This was in both English and Samoan; the Samoan copy was checked by two fluent Samoan speakers for accuracy. Attached to the letter was a permission slip. No student could participate without signed permission from a caregiver.

\section{Contact with Participants}

After the phone conversations with aiga I called a meeting with the 14 Samoan students I hoped would be willing to take part in the study. We had a talanoa about my study, and their experiences of English. We shared food and had informal conversations about school and study and pressures. It was a relaxed and informal talk although as it happened early in the second term of school the students were not as relaxed together as they later became. I gave the students an information letter adapted from the caregiver letter into simpler language; this was also in both English and Samoan. A consent form was also attached; again no student could participate without consenting. An e-mail address was given on both information letters in case any party needed clarification or had any concerns. All participants returned their consent forms before the data collection began.

\section{Initial Talanoa}

The first formal data collection period took place in the third week of Term Two after all consent forms had been gathered. The 12 remaining participants were spilt into smaller groups of three and each group met in a small room during their Learning Advisory Roopu time. This meeting time had been discussed with students, parents, learning advisors and the principal and was decided to be the least disruptive time. Each of the first talanoa lasted 40 minutes and started with a prayer; this was always willingly carried out by a participant. We shared food and drinks and the talanoa was usually started with an open-ended question. In the initial talanoa it began with my asking the participants to tell me about some times when they have felt a sense of pride. The talanoa was recorded on my smart phone audio recorder and then transferred onto my laptop. The students were 
aware it would be recorded and only my supervisors and I would have access to it. They were also assured anonymity in the form of being able to choose pseudonyms, and the exclusion of any details that may identify the school.

\section{Observations}

The observations of the English classes happened over two times of two English classes - one observation in term two and a following observation during term three. During the observations I took extensive notes on what the participants were doing and how they were interacting with each other and the teacher.

\section{Talanoa after Observation}

The follow-up talanoa started the same way as the initial talanoa, always starting with a prayer said by a participant and involving food and drink. All four groups spent between 30 and 40 minutes discussing the English classes I had observed. The discussions were often started with my describing something I observed during the lesson and asking them to comment. The participants often talked to recount the lesson and make comments about why they had chosen to sit in certain places, chosen the topics they did or attempt tasks in the way they had.

\section{Data Analysis}

The audio recording of each talanoa was transcribed by me as I wanted to make sure that I knew the data well enough to pick up on things I may have missed in the talanoa. I also had made hand-written notes about body language so during this process I could make notes about when participants were sitting, or any non-verbal cues they gave. After the transcribing process the first step of analysis was to identify the key themes that emerged in the talanoa. I worked with the transcribed data, and used a thematic coding process to summarise each sentence into significant statements that were then narrowed down into themes. Three major themes emerged from this process.

\section{Ethical Considerations}

This study was granted ethical permission by the Faculty of Education Human Ethics Sub-Committee, Victoria University of Wellington in 2015. The Ministry of Education's Pasifika Education Research Guidelines (2002) informed the conduct of the research. The people discussed in this research were respected and after consultation I selected pseudonyms to protect their identity. All audio-recordings and data that could identify the participants are password protected. 


\section{Limitations}

The limitations of this study were firstly my relationship to the site of research. Although I had not taught the participants, and it was outlined in the information letter given to both parents and participants that if I was to teach them in the following year that participation in the study would not negatively affect their treatment in class, there is still a power dynamic that may have made participants feel as though they had to give certain answers in talanoa. As an adult in a teaching position at the site of research the participants were not talking to someone impartial and may have been influenced by this. I also had taught six of the participants' siblings, which may also have influenced both positively or negatively how they chose to respond to the talanoa.

Another limitation is that the scope of a 90-point thesis did not allow for a more in-depth look at participant data which could have added to my understanding of positive outcomes participants were experiencing, such as achievement data. During talanoa the timeframe also meant the conversations had to finish after 40 minutes and not come to a natural end, which could have drawn out further themes.

The participants involved in this study are also a small group who do not reflect all the important differences and variances of Samoan students in New Zealand. The participants can only provide their own opinions and experiences to offer some ways of understanding how they are choosing to navigate the English classroom. 


\section{Chapter Four: Findings}

\section{Introduction}

Chapter Four begins with an overview of the participants and how they view themselves as being Samoan, the differences between the participants, and how these differences were revealed during the talanoa. Next, there is a description of the process that was followed during the talanoa, as this provides the structure of how the themes are reported. The main section of this chapter reports the three main themes that emerged out of the talanoa and classroom observations. It then concludes with a descriptive table of examples of observed behaviour that were identified by students as supporting learning.

\section{Overview of Participants and Processes}

In the school data all of the participants had been identified as 'Samoan' by a caregiver checking boxes during the enrolment process, and also personally reported as always identifying themselves as Samoan. Two of the participants also identified with Māori as their second ethnicity. From early in the research process, 'outliers' presented themselves in differing ways, adding another dimension to the findings. Despite five participants being born on the islands of Samoa, all of them felt they had "come of age" or grown up in New Zealand. As mentioned in the introduction, the participants who were born in Samoa revealed that although they had completed their primary schooling in Samoa, they had experienced as much if not more schooling within a Western education system so it seemed appropriate to also see my cohort through the lens of second generation. The breakdown of the four talanoa groups was as follows:

Talanoa A: Three male students who arrived in New Zealand between Year 5 and Year 7, and identified as Samoan. For instance, they spoke Samoan at home most of the time and attended a Samoan church at least once a week; they also reported speaking Samoan with friends at school.

Talanoa B: Three male students who were born in New Zealand and reported a link to Samoan culture through speaking the Samoan language at home as well as attending church regularly.

Talanoa C: One male and two female New Zealand born students who reported a link to Samoan culture, speaking the Samoan language at home and attending church regularly, plus being part of the Poly Group at school. 
Talanoa D: Three male students, one who identified as afakasi/half caste Samoan and palagi. The other two students are afakasi/half caste Māori and Samoan. They reported a pride in being Samoan, but little or no understanding of Samoan language and seldom or never attending a church or youth group where other Samoans may attend.

All male participants also played rugby union in the same Under 15 Rugby team for the college, excluding one participant in group A. This is relevant as they reported speaking in Samoan and/or feeling supported at school by other team members.

\section{Talanoa}

One observation throughout the talanoa process was reluctance from the three participants in Talanoa D to "speak for Samoan students"; however, when they found they were reporting similar experiences they began to offer more in discussions. The talanoa sessions early in the year were not nearly as free flowing as later in the months of the research. A few explanations for this were that participants were more comfortable with being recorded, becoming more comfortable with each other and myself, and my attendance at their rugby games was also reported by students as a reason for feeling like they could relate to me. As the talanoa process is meant to be an open dialogue between the participants and researcher, I tried to share experiences and anxieties from my schooling and university. At the end of the research process one participant in each group had mentioned feeling more comfortable sharing with me after I had revealed my own cultural experiences, such as feeling like I did not belong in "top stream" classes, or feeling like none of the texts I studied in school reflected my own family or way of thinking.

It is also important to highlight the often different responses from the students in Talanoa $\mathrm{D}$ to the rest of the participants. In the classroom observations two students from Talanoa D did not start tasks with the same enthusiasm as the other participants. Despite articulating similar preferred ways of completing tasks, it was often not until other students had reported their preference that they would agree, or add their opinions. In the observations the three students in this talanoa group were often slower to start tasks, and when asked about it in later talanoa responded by saying they liked to see what the others did first, and then take it from there.

It was clear from my observations that what the students were doing was positively navigating the English classroom. I use the term navigating to explain ways participants approached tasks, made sense of instructions, asked for teacher input and 
organised themselves. Despite the scope of this study being limited, so unable to draw from achievement data, I can provide comment on their ability to successfully navigate the tasks I saw them engage in within the classes. The subsequent talanoa also provided evidence of a positive attitude towards being in the English classroom. The participants can be viewed as positively deviating because of the assumption these students are not achieving well, as seen in the negative statistical picture that achievement data paint Samoan students in. The following themes describe the ways in which they are choosing to navigate the English classroom.

\section{Theme One: Felagolagoma'i (Interdependence)}

The following section describes the theme of felagolagoma' $i$, or working with, working for, and working interdependently. This theme came through with all participants during each talanoa. When examining the conversations between me and each participant group it became clear from an early stage the importance to the students of being able to work in a collective and succeed for and with each other - and the frustration they experience when they are not allowed opportunities in which to operate this collective achievement. The stories shared during the talanoa frequently addressed their feelings of unity with other Samoan students, a want to support each other and the difference between having concepts explained by friends versus by the teacher. When discussing how they wanted to be able to navigate tasks in the classroom, "together" was often the response. This theme is broken into three sections. Each section will discuss the initial talanoa, and then observed behaviour in the classroom and a final talanoa with the students when they discuss what was happening behind what I had observed.

\section{Supporting Each Other in Learning}

In the initial talanoa with the students there was a strong feeling across all four groups of the importance of supporting one another. Students in Talanoa A described doing things such as handing out books to each other, having pens for the other, carrying gear for each other and offering emotional support. The students in Talanoa A described making the choice to sit together at the front of the class:

Ummm...we kind of sit up the front because... ah so we can hear, coz we used to sit at the back, from the beginning of the year, but we couldn't hear so Mareko told us to all move up the front.

They expanded on this saying that it was not just making sure the others in their group (which in class consisted of eight students, the six in our talanoa and two Tongan boys) were at an optimum place to learn, but that proximity to each other was important 
to them. I observed this in the talanoa session numerous times; when the topic became challenging (emotionally or mentally) they would often move near the person answering, or touch the other person's shoulder. One participant explained that they were all used to being close to people, and it did not make them uncomfortable to show affection - often using the phrase "he's my brother" or "that's how you show your brother you love them". All but one of the participants also stated they were from families with five or more people in the household, so being close with others felt natural. The participants in Talanoa A gave more reason as to why they sat together, saying it was easier to tell "the boys" to be quiet when they were all together. They explained that it is a common thing with the Samoan students in the class to listen to one boy in particular, a Samoan boy from Talanoa A. When I asked them why this boy in particular was listened to, a participant explained he was the captain of the Under 15 rugby team most of the boys played in, and they trusted him to support them in class. Another student responded to this strand of conversation and explained:

We are all looking to each other...We are regulating each other...We're communicating - like we're trying to not get each other in trouble, we're trying to look out for each other..

Many of the participants reported feeling the teachers did not think they could be organised and when they tried to support each other by providing equipment, there was often a comment from the teacher centred on needing to get themselves organised. The unfairness of how this seemed came up often in conversation, one student explaining:

It's sad aye...I noticed he didn't have a pen and we sorted it out so we were ready, but we got in trouble. We try to have each other's backs... so if Ioane isn't organised - I can get organised for him... and the other way as well - it's Samoan.

Although the students often spoke about the frustration they felt when they were not given space to support each other, and the unfairness of getting in trouble for trying to help one another, in certain classes they reported the teachers understanding this was helpful to them. In the four classroom observations I witnessed many instances where they were given the space and encouraged to support each other. In their English classes the students seemed well versed in who had what specific task. Throughout the four observations I recorded over a dozen times where the students showed felagolagoma' $i$. In all the observations the lesson started with sustained silent reading; when the participants entered the classroom the same participants in each class handed out reading books. The two students who handed out the books also collected them when the reading period was finished. When I questioned them on this in the follow-up talanoa, the 
participants said it always happened this way, and they would request what they wanted and share the books out between them. One of the reasons they gave for this was to make sure everyone was settled and ready to work at the beginning of the lesson.

Another example of supporting each other in the classroom was holding leadership positions. In each of the observations two of the participants quietened the others down when the teacher started giving instructions. They explained this to me afterwards as showing respect; they also commented that this particular teacher (the English teacher of Talanoa groups A and B) was Samoan and so felt like one of their more respected family members, thus these two felt an obligation to make sure all the Samoan students showed this respect. The teacher of the students in Talanoa groups C and D offered five minutes at the beginning of the lesson for the students to get organised, not commenting on the distribution of pens from one of the students to the rest. The students commented later that the teacher never remarked on whether they brought their own pen or if one person was responsible, as long as they were organised by the time the lesson started. In the follow-up talanoa the students said that this did not happen in other classes, and the result was they were often told off when asking each other for a pen; one student reported that in English the teacher seemed to understand their need to support each other.

After the first observation of Talanoa groups C and D, one student spoke about the need to break the stereotypes she felt they had in the school, such as always being late and disorganised. When we discussed why it was important to her that the other participants were organised, she referred to a speech that had been delivered in junior assembly earlier that day by a Samoan student, the topic being stereotypes. Maria explained why it had affected her so much:

It was...it was so good...it was like stereotypes...it was like we're so used to getting low grades, low credits like achieved, that we think it's a routine we should go through...like our brothers and sisters went through. Or like our nationality and culture is what everyone expects of us.

When I asked Maria and the others in the talanoa if this was how they saw themselves they were very vocal in rejecting the stereotypes, explaining that they were the first to stay behind and finish work and they knew their parents had high expectations of them. They felt a responsibility to achieve together to break down the stereotypes they felt were not deserved. This also plays a part in the next section, explained as the importance of collective achievement. 


\title{
Collective Achievement
}

The sense of supporting each other for the benefit of the group came through strongly in other ways. The need to support each other was often connected to wanting to make sure they were all achieving. A student in Talanoa B described the different spaces he moves between in his life:

\begin{abstract}
Because I go home and I know what my responsibilities are to everyone... we have our jobs and I know if I'm doing it well...then I go to church and we all sing together and worship together and I know they believe in the same God...I play rugby on the weekends and after school and we work together to make the school and our families proud...then I come to class and it's all by yourself. It's just a different way from everything else.
\end{abstract}

We discussed this concept in all the groups and every student expressed having similar feelings towards the way the classes were set up to achieve alone. Tasks that were set up in which they were able to work together and were all responsible for each other's success were reported as the most meaningful tasks in the classroom. The students reported enjoying the opportunity to collectively compose a writing portfolio of poems during one of the observations, and appreciated both teachers allowing them to peer review the speeches that they had written. In all four talanoa the desire to be able to work together to create meaning was discussed. Many students spoke about the frustration they felt when they were singled out by their teacher as a 'success' when they had felt many of their friends contributed to the task they were successful at. Although they were not sitting NCEA assessments, they also spoke about the setup of exams and other tasks that required individual learning with no input from others. One of the students who had arrived in New Zealand five years earlier spoke of the shock he felt when arriving in the New Zealand schooling system. He explained before arriving he had been hopeful he would enjoy school, he always had in Samoa. But the pressure to work by yourself and achieve by yourself frustrated him:

\footnotetext{
It's actually not quite fair, like once you ask your friend because you don't get it but then you get told off for no reason, because it's actually the teachers' fault...how's it our fault that we don't understand, because they don't write it on the board, and they don't explain it well - so when my friend tries to help we both get in trouble - and we're trying to explain it to them and they [the teachers] don't believe us. For me that was hard...
}

The student here went on to explain that in Samoa he understood the teachers' explanations better - but more than this, the climate of the class was one in which he felt they could all support each other. The other participants touched on this topic providing examples of always being proud to win awards - but that pride was because you made your family proud and that they achieved alongside you. The students also explained that 
in Samoa they felt the teachers expected high achievement, which they were not always sure of in the New Zealand classroom. This theme will be discussed further in the final section.

During the first classroom observation I noticed one of the students questioning why the other had not yet finished his speech which was due the following day. The students had been given two weeks in which to write the speech, one week was dedicated to in-class time learning about structure and language features, and the other was given to in-class writing. The six Samoan students in this class were sitting together; five of them were at the stage of writing their speeches on cue cards. Ioane, however, was still writing in his exercise book and Mareko watched him for a minute and commented on how far he had to go in a frustrated tone. The class environment allowed the students to talk to each other as the teacher monitored students at the back of the room. The conversation was in Samoan and although it was not heated, both of the students were frustrated with the other. When we met again and spoke about the lesson I brought this up. They explained to me that they spoke in Samoan so other (palagi) students would not know what they were talking about. One of the students then explained he was angry because Ioane was not doing the work and may fail:

R: Tell me about that, how did it make you feel?

M: Angry at him because I want him to succeed!

$\mathrm{R}$ : And why is his success important?

M: He's like a brother to me...he's really smart and he could use his talents to go further in life.

This sense of responsibility for one another was shared by the girls in Talanoa C who responded to my observation that in class they checked each other's understanding of new instructions. They explained that they appreciated their teacher always allowed them to talk after giving instructions for a short amount of time so they could ensure everyone knew what they needed to do. In this lesson the learning intention was to understand specific language features and how they could be used to make their speeches more interesting. The girls in Talanoa $\mathrm{C}$ sat at a table with other Pacific students, and each of them checked over each other's work and took turns highlighting the language features they recognised. An example of this was pointing out the rhetorical question: "Why should my skin and your skin colour define how we receive recognition?" Maria had included this in her introduction, having been earlier inspired by the speech delivered in assembly. The students then spoke about how it was effective, this idea was then adopted by another one of the participants in the context of her own speech. In the following talanoa to this observation I asked if this was common in their group and 
whether the other students in the class also made sure the rest of their table was achieving. The girls explained:

We're all like best friends - we want each other to succeed... Miss M lets us explain things to each other - that's different from other classes and different from the palagi students, when you ask them for help they just say - oh go ask the teacher. But Samoans are like, oh come here...

They went on to say that often they thought they were looked on in some classes as the trouble makers, and a few of them felt that to rid themselves of this characterisation they needed to work together. One group who differed slightly from their comments on collective achievement was Talanoa $\mathrm{D}$; despite reporting they preferred to work in groups and receive support from their peers they did not have the same reaction to succeeding as a collective. Two of these three said that it made no difference to them whether the group they worked with was Samoan students, and that they did not often feel responsibility towards other Samoan students, although they did say they wanted others to succeed in class. The students in this group did not attend church with other Samoans, nor did they speak Samoan at home. In the last talanoa one participant said he felt that if he was able to speak to the other participants in Samoan it could support him more in class. He was not able to explain why he thought this.

\section{Learning from One Another}

Another strand of felagolagoma' $i$ in the classroom was learning from one another. In every talanoa the students mentioned different versions of when the other students had helped them understand concepts or tasks better than the teachers' explanations. During the initial talanoa we spoke about how one of the students had had to miss a significant amount of school due to the passing of her father. She said it was hard to come back to school as she felt so far behind. In many of her subjects the teachers had tried hard to support her in catching up; however, in English she felt the most supported. One example of being supported was the teacher giving the group time to read their poems to her and explain the tasks in Samoan. This was mentioned in the second talanoa when the conversation turned to difficult instructions. The students described sometimes feeling overwhelmed by long instructions and when asked how they navigated these tasks said it was easier to understand when they were allowed the time to discuss the requirements together. One helpful strategy they said was they were often asked by the teacher to reword the task in 'student friendly language' so she could assess for understanding. Although they stated they very rarely re-worded tasks in Samoan, they felt the teacher would be supportive of this - and being given the opportunity to discuss success criteria 
as a group and "break things down" together helped attempting the task with more confidence. In the follow-up talanoa I asked if they did this in other classes, which they reported not to. I asked if it may be helpful and one participant recounted rewording instructions for her group in another class, and the teacher asking her to do it for the class. She felt positive about being able to, and when prompted said they would like the opportunity to share their understanding of tasks in each class.

In my second observation of one class students were preparing a writing portfolio of poems. One of the tasks was called "A letter to myself in ten years", and Mareko was asking for clarification about what this meant. Two other participants went on to explain, and then read their own poems so Mareko would have a better idea of what this could look like. Another requirement of the portfolio was to include at least three language features across the three pieces of writing; towards the end of the lesson participants in one group went through each other's writing debating whether they could use the same language feature (in this case a metaphor) twice. Two argued that they had to be different types of language features and reflected back on what they had written in their own success criteria. It was decided they needed to be different and so re-worked one piece to add a simile. In this lesson the girls who were finished with the tasks were writing haikus and trying to decide on interesting adjectives to replace what they called boring words. The girls worked together suggesting words the other could use. In the follow-up talanoa I questioned what the benefits of having their friends explain things and make suggestions were. One of the explanations was because they felt they could ask more questions to a friend. The girls said they treasured their individual time with the teacher and felt very supported by her, but knew that in a big class they could not get individual attention all the time. One student explained:

From your friends it's easy - they tell the truth...because teachers can be like "Oh yeah, it looks alright", but they're really thinking it sucks! But your friends will say it sucks - change this bit!

They added to this saying that when you work together you get more ideas and get to share your ideas without feeling like they have to be fully developed. The high expectations of the teacher played into this sometimes - they often wanted the teacher to see their best work and so liked to be given feedback from their friends before submitting a draft. Talia explained this in reference to Miss M saying:

Miss M is softly spoken, she never raises her voice... she's Samoan and she expects a lot from us Samoan kids... she expects more... and it kind of feels good because she's trying to push us...No one wants to disappoint her so we help each other in class first. 
The participants also felt the other Samoan students broke things down for each other in ways that they understood, which gave them more confidence because if all of them had the same or similar understanding it meant the they were all probably on the right track.

\section{Theme Two: Filifiliga Sa'oloto}

The second theme that came through clearly in both the talanoa and the observations was filifiliga sa'oloto which is the concept of having the freedom of their own opinions without fear or pressure. When this is happening in the classroom it requires the teacher to regard with importance any opinion given and to accept with respect a decision made by all students as their perspective, as their choice. Another way of describing this is the freedom of autonomous learning, and the opportunity to bring their own experiences into the classroom. This was referred to in a number of different ways throughout the conversations, from the teacher showing an awareness of the influence and importance of their aiga, to the position church plays in their lives, and finally the value of being able to personally engage with tasks in the classroom.

\section{The Influence of the Aiga (Family)}

The influence of the participants' aiga or families was discussed in all talanoa sessions to varying degrees. Many of conversations around this topic were very emotional; the participants clearly had a strong feeling of pride and deep responsibility to their families. One participant explained this in the second talanoa as a reason he wanted to understand how to succeed in his subjects:

\footnotetext{
It's embarrassing when you feel like you don't understand anything, when people look at you and when they look through you, you see that they can see your mum and dad like...you know like you're upsetting your mum and dad [strong agreement form the other participants]...they see my mum and dad through me...For me it's hard because my mum has gone to Samoa and my dad always misses me... and I just try to make them proud.
}

The student was visibly upset; the other students reacted by moving closer to him and agreeing. All participants provided other examples of wanting to make their parents proud and feeling like they were representing their aiga and therefore wanted to succeed in school. Wanting to make their families proud was often mentioned alongside their understanding of the sacrifices their families had made in order for them to attend school in New Zealand. Although half of the participants had not been to Samoa before, all of the participants had at least one parent who had been born in Samoa. In the first talanoa every group mentioned the sacrifices they felt their aiga had made to ensure they received 
a good education. They spoke about the resources that were available in New Zealand, such as technology, equipment and opportunities to earn a better living than their parents had. They also spoke often about the high expectations parents had of them, and how it added to a sense of achieving, not just for them, but to ensuring they were making sure the sacrifices made for them were worth it. When I asked Ale to expand on whether he felt this caused positive or negative pressure he clarified:

Home is where it starts...everything you know starts at home...My parents have worked hard just to give us a better life - because in Samoa it's different to here, because it's hard to find a job - you can work in the plantation, but it doesn't get you anywhere - so when they brought us here, we just want to help them. There's so much support behind you... it makes you proud.

Another student, Liva, described how his aiga provided support when he thought about them as he was at school. His journey to New Zealand he felt had been a disappointment to him; he had pictured it differently and often felt lonely and misunderstood, but the sense of grounding his parents gave him made him feel that he could achieve well and make them proud. He spoke about his parents giving up everything to come to New Zealand, and how much they worry about him:

In Samoa every day after school I'd do my chores and go out...I was allowed to go out, but here, I do my chores and stay home... it's just getting lost. My mum doesn't want me to get lost...In Samoa though it's like, yeah - you can go out because they know the village and the village knows you.

The concept of being looked after by more than just his own family came through in many different ways across all the talanoa. The students pointed out that in New Zealand it seems like you achieve for yourself and no one really knows what your parents want for you. They felt if teachers had a better understanding of their home life they may feel more of a connection to school. One student explained that in Samoa you know your neighbour, you know all your teachers personally, you know their kids, and it gives you a feeling of safety. This is reflected in how they viewed their most positive relationships with teachers in New Zealand, which I will discuss in the final theme.

During the silent reading at the beginning of one observation Michael was the first to be seated and ready to read; five students arrived late from PE and were noisily collecting books and discussing the previous class. Michael continued reading unphased without looking up or acknowledging the noise. I asked Michael in the following talanoa whether he had been distracted by the noise and he responded by saying he always read at home, his mum encouraged reading, and the house was always noisy so the classroom noise did not bother him. The skill of reading without distraction had been encouraged 
and perfected at home. Another student, Tanielu, during the class had been trying to choose a speech topic with the teacher. With help from Mr F, he had settled on the importance of learning about Samoan history, and he spoke to Mr F about the Mau movement in Samoa who seemed very interested. Tanielu had a hard year and, according to a few teachers, found settling in class very difficult, often being distracted by what was happening outside the class; however, when the teacher walked away he started researching the topic and showed the two other students at his table the topic he had chosen. He also asked if he was able to take his speech home to work on. In the followup talanoa to this lesson I asked about the interaction with the teacher, and his question about taking the work home. Tanielu explained that he knew his dad would be proud of him for learning about the Mau, and that it felt good when his dad was able to help him with work. The opportunity to share what he was learning, and be able to bring his dad's knowledge back into the class with him was obviously very important to him. It was interesting that Tanielu up until that interaction with the teacher had shown less enthusiasm about identifying as Samoan than the other participants. He was often last to speak in our talanoa, and one of the members of Talanoa D to report not having the same feelings towards achieving as a collective; he also was the only participant who sometimes sat by himself, or reported not always preferring to work in a group with other Pacific students. After deciding on the topic of the Mau however, he moved groups to sit with the other Samoan participants. When I asked why he moved he said he could not remember why; when I asked him if it was because he felt happy with his topic he responded that he was proud of it. He did not expand on why it made him proud.

The second observation with the other class (Talanoa groups A and B) showed some similar examples of bringing lessons they had learnt at home into the classroom. Mareko, quietening down the boys when Miss M began to give instructions, explained to me it was a value he had learned from home:

You have to be respectful, all the lessons we learnt, like working hard and being respectful we learned from home...Palagi students don't do that. They talk back kids from Samoa would never talk back.

When we discussed this further the students believed this was one way they were able to operate their "Samoaness" in class. They did not want to be a different person in class than they were when they were at home. Aiga in this way was ever present, and it was important to carry their home values into class; however, they also felt there could be many more opportunities to do this, suggesting that not all teachers knew their families, 
and the ones that did made a huge difference to them. Expectations and encouragement were described as a positive thing:

It's a huge challenge but it helps...it gives us strength.

\section{Church Influence}

Of the twelve participants, ten reported attending church weekly; out of these ten, five of the students reported attending church at least twice a week, describing it as the most important part of their lives. In the initial talanoa when discussing reading many of the students said they read the Bible often in both Samoan and English. One student, Samuelu, talked often about reading the Bible and trying to understand what the lessons behind the passages he read were. The first time he spoke in the talanoa he described a famous preacher speak at a conference in Wellington; this was the most animated he was during all the talanoa we had together. Samuelu described how learning about the teachings of the Bible made him feel like he could overcome not having his parents in New Zealand. Other students echoed how much the church influenced how they lived day to day. Eight students also remarked on memorising passages, and which passages they chose to memorise. Michael spoke about choosing passages that meant something to him personally, passages with ideas on how to deal with hard situations, or ones that gave him hope. The other students echoed this sentiment, adding that is why it is important to understand exactly what they mean. The students discussed how this skill of finding the underlying meaning in a passage helped when they were in the English class:

\section{Yeah, we know how to do that...I just read it over and over again...It's important} to know what it really means... especially if it a verse that really touches you.

This idea of choosing verses or topics that touch them was apparent in observations. In the first two observations both classes were working on their speeches. One class was at the stage of deciding speech topics. Samuelu had chosen to talk about his religion and was discussing with the teacher how he could make sure that the topic suited the audience he was speaking in front of. It was an interesting conversation to observe as the teacher felt the student may be isolating himself slightly by speaking on a topic that some of the students may not have an understanding of, or view with the same passion as Samuelu. The student, however, did not seem aware of this. Samuelu was excited to share with the class something he felt so strongly about and commented later that this was one of the topics he knew well and wanted to share this knowledge with classmates. When we discussed this in later talanoa he still felt he had made the right 
choice, and was acknowledged by the teacher as choosing a difficult topic to discuss as a teenager. He reflected:

It's confidence Miss, that's what church teaches you...I've watched preachers my whole life...I was always going to do this speech.

In my observation the other Year 10 class was further along in the process -their learning intention for this particular class was to memorise the speech and consider how using body language and tone could add interest for the audience. Ioane and Mareko asked to leave the class part way through this lesson to practise outside. I observed them as they read the speeches out loud to each other. At one point Mareko suggested Ioane look up more, and use a hand gesture when making his point. Ioane timed Mareko, saying he spoke too fast and needed to slow things down. When we discussed this technique of memorising at the follow-up talanoa, the students in the group all laughed and explained they had been memorising passages since they were young. Each student discussed the upcoming White Sunday, an important religious holiday in Samoa centred on children. I asked the students, when they are in the English classroom do they ever think "I've done this before"? and the students all said that they were well aware they had this skill, and that it was learnt outside the English classroom. They also pointed out they knew how to structure their speeches due to how standards and passages are written:

Miss M told us when we were learning structure - Oh, you know this, because it's just like how verses are structured. She might let other kids not stand up in front of everyone because some kids don't like that. But she wouldn't let us Samoan kids not do it...she knows we can even if we complain a bit.

In this example it was not just the students who were aware they had the skills to structure and deliver a speech, the teacher was also aware of their skill level. A combination of strong relationships and high expectations meant all the students achieved well in their speeches. After they were delivered we discussed whether they were happy with the results; all the students felt they had done a good job. Talia commented:

\footnotetext{
We feel more comfortable in here than other classes. She [Miss M] knows what we can do and doesn't let you choose if you're too shy or not. She knows we're not. She goes to church too and has kids; she knows what we can do. Last year I didn't even do my speech...I knew my teacher then wouldn't make me.
}

Similar to the support and strength they feel is behind them with their aiga, the majority of the participants felt the same about the influence of the church. It was a translatable skill they knew how to operate in these two different situations. The familiarity of speaking in front of others provided confidence in themselves to tackle the task. Filifiliga sa'oloto is operating as they are being empowered by their own knowledge 
and experiences; both teachers in this case valued the choices made by the students, and encouraged them to use their prior knowledge to successfully complete the task.

\section{Personal Engagement}

Another way the theme of filifiliga sa'oloto came through in the talanoa was in reference to tasks that allowed personal engagement and choice from the students. The early talanoa often focused on when the students had felt successful, and the circumstances surrounding the success. The students reported that when they were able to make choices for themselves, choices about the topic they would write on, or the book they would choose to read, they felt more confident. It was explained to me by one participant who said:

I would always choose to write about something I am interested in, but know something about, because there's so much things in English we don't know about...it's better to start with something that doesn't make you feel stupid.

This was echoed many times in the early talanoa sessions. The students told me about wanting to read about Samoa and study Samoan texts, but not being sure there were any to study. Mareko stated that even Samoan myths and legends would be interesting. When I asked about why it was important to him to study his culture in class he replied:

We study their [palagi students'] stuff all the time...if they knew some of our stories, of our stuff then we could all relate better...that's just what I think...

This need to see themselves within the lesson was mentioned many times across all the talanoa; in one session Maria talked about liking that Miss M gave them a range of topics to write about for their poetry unit:

I liked that unit...we had three poems to write...we had to make up our own...one about childhood...one Haiku and the other was a letter to yourself in ten years...so it was like a time capsule. It was good because you couldn't be wrong, you know? No one can turn around and say - hey that didn't happen like that!

Throughout the observations personal engagement was a big factor in whether the students reported enjoying the task or not. Even at the very start of the lesson the students who were reading books they had chosen themselves was a part of whether they remained engaged in reading the whole ten minutes. When we spoke about this three of the boys recalled having been given rugby books and really enjoying them; the fourth boy, Ale, had been given a book on religion and was engrossed in this also. They explained the teacher, Mr F, had picked out books he thought they would enjoy, and left them in class in case the students did not bring their own. Mr F also made sure they had opportunities to go to the library and borrow a new book every two weeks or so. 
I also witnessed a part of the second lesson I observed where the students were required to recall any language features they could remember and explain why they were used. Tanielu in this lesson had been staring out the window, leaning back on his chair and fiddling with his pen throughout this part of the lesson. As the other students reacted enthusiastically to calling out the names of language features while Mr F wrote them on the board he remained distracted. At one point the students were asked to provide an explanation of the term "to persuade"; at this point Tanielu shot his hand up and called out "I know this one!" He became animated and explained it to the teacher. For the following part of the lesson Tanielu remained engaged and began writing the list in his exercise book. In the follow-up talanoa to this I asked Tanielu about how he had been feeling during this part, and after he had answered the question correctly:

Oh you just zone out when you don't know...I look at the wall and hope not to be picked...but when you know it's like - oh that's mine!!

We discussed how this could be compared to playing rugby as a team in the talanoa; the boys seemed interested in this idea, describing knowing where every one's weaknesses were and knowing when to take the ball and when to pass it. They felt they worked like this in class, and felt a sense of pride when they were able to help out with answers, which made them more likely to persist in a task.

Persistence and the ability to engage in tasks also came through in the lesson when the students read their poems to the other members of the group.

\section{Theme Three: Fa'ataua}

The third and final theme is fa'atua, or to regard others with importance, and to be accepting of others' opinions. This concept centres on positive relationships, and affording everyone the same opportunities to discuss ideas openly, pose questions and provide an opinion. In the classroom it is operating when all students feel a sense of importance and are given an open forum to discuss matters without fear or intimidation. The importance of feeling heard and having the confidence in the classroom to speak up and give personal insights and opinions was clear from the first talanoa sessions. The students discussed how invaluable it was to have a strong relationship with the teacher where mutual respect was the cornerstone, also how the atmosphere of the classroom could promote achievement, and finally the effect of being misunderstood when these two things did not happen. As the thesis question focused purposefully on the students' experiences in the classroom and not the teachers' opinions of how the students were 
learning, this section attempts to privilege what I heard and observed of the students in class, and not what the teacher was doing at any given time.

\section{Relationships Between Student and Teacher}

In the first talanoa sessions with all of the students, the four groups had the opportunity to provide examples of a teacher they felt they had a positive relationship with, and the effect this had on their ability to succeed in the classroom. At first they discussed any teacher, whether it was a parent, friend, coach, past or current teacher in any subject who they felt helped them learn. In these talanoa the students often described teachers who they felt knew them personally and showed an interest in who they were as people, and also had an awareness of their families and culture. Sione described his experience of being in a primary school class with one teacher:

Ummm...my primary teacher...he was old. I liked him because he knew my parents, and he was Samoan too. We related to him the most. He'd speak to me in Samoan so I never felt as lost.

Sione felt comfortable that what the teacher found important, his parents also felt important so it gave him confidence in class to be himself. He went on to explain that they both expected a lot from him and so he never wanted to disappoint them. In this same talanoa Paul described a social studies teacher at the school as his favourite for a similar reason:

Miss D! She's an islander too! She knows like, what we're like! What we understand and what we find difficult!

In Paul's perspective, Miss D understood he could not understand long instructions and that she needed to give them a chance to fully understand them before moving on. He said she always gave instructions in a variety of ways, from writing them up, to drawing diagrams and having each group discuss them. He brought up a theme that was echoed in each of the talanoa groups, which was the idea of being allowed to know about the teacher as a person:

You know when Miss D's dad died? She showed us the photos [of the funeral in Tonga]...it was special...it made me wanna stay in her class...not many other teachers would do that.

The other students in the talanoa group added to this saying even though it was hard for her, she showed them trust and they treasured that trust. In Talanoa $\mathrm{C}$ the participants spoke about teachers who took their time to explain strategies and not make them feel stupid: 
Mr F...he tells us this and that, and then even if we don't understand he know us well enough, so he like prints something on the board...like a reminder. So you are reminded. But he still wants you to know it... he's still strict.

The students often spoke about teachers who were firm and fair and expected the students to learn, but had an awareness of the students' abilities. In Talanoa B, one participant spoke about a teacher whom he had originally disliked:

Oh Miss H! I hated her at the beginning, but I liked her in the end. She pushes you so hard...she believes in you, you know that. She wanted me to have a good grade just like my mum! But she also knew... where my gaps were?

Within the classroom observations I observed the relationships between both of the teachers and the Samoan students in the class. In the first observation of Talanoa groups A and B the students arrived in class after a PE lesson. Three of them were five minutes late and had to settle into reading along with the rest of the class. During this time the teacher was modelling reading and did not respond to the interruption of the latecomers. The participants who were late were obviously well versed in the routine and immediately found a book or magazine from the front of the class, joined a group and began the daily practice of silent reading. It was not until after the learning intentions had been explained and success criteria discussed that the teacher approached the latecomers individually. In the follow-up talanoa to this lesson I asked Ale (who had been late to class) about this interaction. Ale explained that Mr F never called anyone out, and he described the deep sense of shame he often felt when he was singled out in front of his peers. It was not only the feeling of embarrassment in front of friends but the deeper feeling of letting your 'side' down. He felt a responsibility to the rest of the Samoan students to be a leader, and when his lateness was 'called out' without being discussed first he said this made him not want to come to class if he was going to be late:

$\mathrm{Mr} \mathrm{F}$ is cool. He understands there can be a reason, and if there isn't he will make you stay in, but he finds out first you know? Some teachers don't really care - they ignore you or...make you feel shame.

The relationship that Mr F had developed with the participants meant he was aware that to put the students on the spot often resulted in a feeling of shame, and caused the students to refrain from offering their opinions or answers in class. The students also pointed out that a variety of learning opportunities were provided to them so they were aware of the expectations in class. Instructions were discussed verbally, there was an opportunity to discuss them in groups, and finally they were written on the board in simple language so the participants could refer to them throughout the lesson. When I asked the students if they were aware of why the teacher did this, it was clear they knew it was 
because the teacher was aware students learn in different ways, that is was a deliberate act.

In the first part of one lesson the students were asked to recall language features that could be used in their speeches to make them more interesting. A few suggestions from the class were hyperbole, emotive language and interesting adjectives. The students explained in the following talanoa they had learned these earlier in the year during a poetry unit. Samuelu, who was sitting at the back alone, did not discuss the instructions with anyone and was hesitating with starting the task. However, within a few minutes he had read the instructions on the board and had begun working. When I questioned him about this he explained that Mr F always made sure if you were lost then it was written up on the board, but also encouraged the students to discuss the tasks to develop a shared understanding:

You know you go into some classes and they are all quiet, like dead. In English there's lots of talking, he knows that's how we roll... He knows we know the difference between that bad noise and that good noise.

Fa'atua was also present in the classroom relationships when the students were asked to carry out a task that they were unsure of. In the middle of this lesson the teacher wrote up the words 'to persuade' and asked the students to come up with a definition. There was a very physical and noticeable reaction from the class. Up till this point the atmosphere was relaxed, and body language was open, and apart from chatting about the tasks there had been no 'off-task' behaviour. When the unfamiliar word was written up I observed the following behaviour: Ale pulled his scarf up over his face and looked away, Sione rocked back on his chair and appeared to be reading a poster at the back of the classroom, both Paul and Johnny tapped the desks with their pens and began to talk quietly about the upcoming rugby game. This lasted less than a minute before the teacher responded, saying - if we don't know then what should we do? The students suggested asking a friend or looking on dictionary.com or in the dictionary. The participants immediately refocussed and one student, Samuelu, collected dictionaries and handed them to the other students. In the follow-up talanoa I asked them about this reaction to an unknown word:

You feel shame... and scared... when you don't know the answer...but Mr F tried to make it safe to not know. He just wants you to do it.

In the second classroom observation fa'atua was shown to the students by Mrs M when participants were finishing writing their speeches. One particular example of the obviously positive relationship between the students and teacher was when Mrs M was 
monitoring students and approached Liva. Liva was at the finishing stages of writing his speech and I observed a page of writing he had crossed out and he was staring at. An interaction then happened where the teacher spoke to him, briefly questioning him in Samoan; the interaction was gentle and allowed for moments of laughter. When Mrs M moved away to help another student, Liva re-wrote the page he had crossed out. Following this observation I questioned what had happened to make him use the part he had originally crossed out. Liva explained that he had been unsure because he felt his writing was too impassioned:

I ummm....I always have the feeling that it's not right - so I have to write it again... I just always think it's incorrect. Mrs M made me feel proud though.

When I asked what they had been discussing he said she had read the speech back to him and asked if he agreed with what he had written, and she explained sometimes you need to hear things in someone else's voice and assured him that it was well written. Liva felt that the atmosphere she cultivated in class and the support she gave them made them far more willing to take chances.

\section{Cultural Dissonance}

The final section discusses the students' experiences of being misunderstood by the teacher in the classroom and how they felt this affected their achievement and often made them reluctant to participate in class discussions, or offer their opinions when it happened regularly. The students explained that regularly meant at least once a week and they felt some teachers did not understand their intensions. Much of this section is based on talanoa sessions as I rarely observed what was described in the English classroom observations. It seems important, however, to include as the students identified examples of being misunderstood in all of the talanoa sessions. Although this has been described in the first two themes with instances such as getting in trouble for helping one another and feeling unsupported when they were unsure of instructions, this section will focus on teachers reading the participants' intentions wrongly, and the effect this has on the students' motivation to participate.

In the first Talanoa three students mentioned instances where they felt the teacher did not understand either their intentions or the student themselves in terms of being culturally located. One example of this was Maria explaining a period of time when she was away from school. Maria had gone to a funeral and missed a week of school. She described being reluctant to return as she was concerned she had fallen too far behind. The other students described similar instances where they felt their family obligations 
were not understood such as being responsible for younger siblings who attended the primary school or intermediate in the close vicinity, which sometimes led to their being late to the first class, or attending a late church service, for which they felt the teachers blamed them for being tired. One student said he felt he worked very hard in class but because the teacher was aware of other commitments every time he was tired she pinned it on his family. He did not feel this was fair. Talia expressed the frustration she felt with teachers who did not ask about what they had been doing when they were absent, and instead focused on the work they needed to catch up on. Maria explained she wanted to catch up on the work, but when she asked how she could do this she was unclear about the instruction. To her it felt as if she was being punished for attending a very important event for her aiga:

It makes you feel dumb. When you come back and ask for individual help, like...them coming to help you - and not just like telling you one thing, and you ask for more information about it and they just ask another student to help you. It's like you're not worth teaching in some classes.

The participants involved in this talanoa explained while this does not happen in the majority of their classes, it has a huge effect on them when it does. They described feelings of not feeling worthy, or resenting a teacher who did not give them the same amount of time as the other students. When I asked whether they felt it was due to their being Samoan, one student, Talia, clarified that although she did not feel it was racially motivated, she did think that if the teacher understood more about their sense of responsibility to their families it may not happen.

Another example of being misunderstood in the classroom was Tanielu's story about being singled out in class. Similar to feeling pride for himself and the collective when he succeeded, he also felt a collective shame when he was singled out in front of a class for not understanding content, or for misreading instructions and giving incorrect answers. Tanielu was a reluctant speaker and much preferred to offer his ideas in small groups of peers. During one talanoa session he described feelings of anger when he was placed on the spot in front of his peers to feedback his answers:

\footnotetext{
You know when they're [the teacher] just trying to make a point out of you. You know when they think you don't know and they embarrass you like a warning to other kids and that's not fair. They just ask us straight up in front of everybody, like sheeeeesh!
}

He said in these classes he spends most of his time avoiding eye contact and trying to not be noticed. The effect of this is that he can often miss important instructions, and says that he would only put his hand up once a week, if he was certain his answer was 
correct. In a class like this he said it was a zero percent chance he would take a risk and answer a question if he was not sure.

In contrast to this, an example of fa'atua working well happened in my second observation of the English class when Mr F gave the opportunity for students to come up with the definition of "to persuade". The students were offered different ways in which they could gain the information, and one student was able to volunteer to share the group's answer. In the talanoa Tanielu said he liked this strategy, that it meant he did not have anxiety about being singled out, and so was more likely to share ideas that he thought may be wrong. Ale shared similar thoughts on this, explaining that his relationship with Mr F meant it was one of the few classes where he would raise his hand to participate; he said in most classes, however, he did not feel like the atmosphere was safe and other students would laugh if he got the answer wrong. He felt Mr F was very clear from the beginning of the year on his expectations of the class accepting answers, and that even when Ale answered incorrectly Mr F tried to figure out where the reasoning came from. Often, he said he would have an impulse to put up his hand in other classes, but if it was not noticed immediately he would retract it as he began to feel shy:

Mr F notices when you put your hand up just a little bit, like a signal you know? Like here I am but I might be wrong... and if you change your mind he'll like prompt you...smile and stuff. Some teachers think you're being silly.

In this example the students explained that this teacher understood the difficulty of offering opinions and does not misunderstand their reluctance as playing the 'class clown.' In this talanoa the students said sometimes they felt embarrassed when they gave a wrong answer and would laugh, and this had led to a few of them feeling they had unfairly been labelled as not taking the class seriously.

In the final talanoa with the students all groups in different ways expressed that they almost anticipated being misunderstood in particular classes; conversely, they were very clear about the classes they felt they could take risks in and felt comfortable and confident that what they offered would be respected and accepted as valid. For these participants, when fa'atua (to regard others with importance and to be accepting of others' opinions) was operating in the classroom the students were far more likely to participate. Fa' atua is behind their feeling heard and having the confidence in the classroom to speak up and give personal insights and opinions. 


\section{Chapter Five: Discussion}

The primary aim of this research study was to explore Samoan students' perceptions of the strengths and skills they bring to the English classroom, and how they view themselves using these to navigate teaching and learning requirements. In the literature describing Pacific learners' experiences of schooling in New Zealand, the key themes often include barriers such as teachers' negative perceptions of students, students struggling to comprehend tasks, and students' feelings of not belonging or feeling engaged in learning tasks (Fletcher, Parkhill, \& Fa'afoi, 2005; Nakhid, 2003; Siope, 2011). The findings of my study showed that the group of Year 10 Samoan students had a strong perception of their own strengths and skills, could recognise these as supports within the English classroom, and (when teachers did not underestimate these students' capabilities) would use the skills they had already mastered outside the English classroom to gain positive learning outcomes. These positive learning outcomes were measured through classroom observations that showed on-task and enthusiastic engagement with tasks set and talanoa with the students confirming confidence in achieving in English.

The findings of this study were consistent with the general themes about Pacific learners such as the value of group work, the importance of positive relationships, and a preference for hands-on interactive tasks in the classroom.

\section{Polycultural Capital in the English Class}

Polycultural capital is a useful theoretical paradigm to apply to this research on Year 10 Samoan students in English because it captures the sense that if participants in Pacific education understand how a group functions well, it will have benefits for the other Pacific learners. When the students were able to organise themselves they could successfully navigate the English class with the strengths they already possessed. Polycultural capital takes a positive deviance approach, which is "the observation that in most settings a few at risk individuals follow uncommon, beneficial practices and consequently experience better outcomes than their neighbours who share similar risks" (Breggren \& Wray 2002, p. 9, cited in Mila-Schaaf, 2010). Initially used and applied in the health sector, positive deviance recognises that solutions to problems already exist within communities. The implication of positive deviance for this education study is that Samoan students who are successful already may offer paths to positive learning outcomes for others. 
The participants of this study clearly knew and could articulate how "good learning" took place. They articulated feeling successful when they completed tasks or were able to provide support for each other, and knew the factors that enabled this success. Within observations the participants actively tried to allow these factors to happen; examples of this were asking “can we do this in a group?" or asking peers, "what does she mean, have you done this one? Can you explain...?" Positively deviating from negative statistical representations in national data, the group of Samoan students in this study reported feeling successful in the English classroom. As well as reporting feeling positive in the talanoa sessions 'positive learning outcomes' were also recorded using an adaptation of the observation tool developed from Tataiako by the Kia Eke Panuku team at the site of research. As mentioned in the introduction, the original Tataiako tool was developed to record evidence of positive learning for Māori students, and although Māori and Pacific learners are not an interchangeable homogenous group, there are some useful indicators I was able to use to record positive learning outcomes in the English class. The tool used at the site of the research records evidence from learners' behaviour such as having warm, responsive relationships with teacher and peers, speaking about learning with teacher and peers, sharing their views with the teacher and peers, learning happening with others, exhibiting a sense of comfort and belonging, and being able to bring what they already knew to the learning taking place. These indicators provided an additional tool (as well as observations and talanoa) to explain how and why the students were positively deviating from the normal statistical picture and gaining positive learning outcomes.

In health research, Marsh et al. (2004) described one factor of positive deviance as identifying groups who have had good outcomes despite high risks, and interviewing them to understand some of the enabling factors that could explain the good outcome. In this research the enabling factors for the students were a strong sense of cultural efficacy and identity, support from aiga and peers, a confidence in their own ability to complete tasks, and high expectations of themselves and their peers. In talanoa sessions the students reported not only knowing how they learned best but why they preferred specific ways of learning that were connected to skills learned outside of school.

\section{Samoan Students' Perceptions of Strengths and Skills}

This research study supports what many government initiatives and research studies (Alton-Lee, 2003; Edwards, 2014; Ferguson et al., 2008; Fletcher et al., 2009; Fletcher et al., 2005; Fletcher et al., 2008; Gorinski \& Fraser, 2006; Sturrock, 2004; 
Taleni, Parkhill, Fa'afoi, \& Fletcher, 2007) have claimed about Pacific learners. However, I would like to argue this research extends upon general themes (the importance of positive relationships between teachers and Pacific students, preference for interdependent learning, the importance of using a familiar context for learning and the importance of providing opportunities for bringing their prior knowledge into the classroom), by looking at what it feels like to be a Samoan student in an English classroom, and students' awareness of where and how the best learning outcomes are happening.

\section{Felagolagoma'i}

The first major theme of this study, felagolagoma' $i$ or working with, working for, and working interdependently, seen in the observations and subsequent talanoa, revealed the students' awareness of what was working best for them in the English classroom, and why. Two examples of past studies that deal with the importance of interdependence for Pacific students are Dickie (2011) and Fletcher et al. (2008) which had methodological similarities to this study. Both looked at students' perceptions of what worked for them within the classroom, but within the primary school context. Dickie highlighted the need for teachers to understand that Samoan students constantly have to negotiate one set of values for another and that between the sites of school, church and home the values were contradictory. Similarly to the present study, Dickie points out it would be useful for teachers to be aware of this and use the strengths that come from different sites to support literacy learning. Both Fletcher et al. (2008) and Dickie (2011) see the pathway to finding and utilising students' skills is through the teachers' awareness of these skills. The findings of this study suggest that the students are aware of the skills they have, such as the ability to memorise long passages and comprehend the underlying meaning of texts developed through Bible literacy. The students understand they possess the skill, know how they developed it, and know when to apply the skill. They know that they work better in groups, and make a connection to the parts of their lives outside of school where they successfully operate this interdependence. The participants explained it was not teachers who set up the conditions in which they could best succeed, but they themselves and their peers. The application of this existing autonomy worked best when the students were given the space to employ the skills they already knew they had. Fletcher et al. (2008) highlighted two of the factors that supported success for Māori and Pacific students as positive student teacher relationships and small group work. Similar to the major theme in this study, Fletcher et al. explained collaboration and co-operation facilitated learning 
for Māori and Pacific students. This thesis supports Fletcher et al.'s findings for specifically Samoan students' perceptions of themselves, and provided an insight into student understanding not only of what works, but also why it is working, taking an appreciative approach to understanding learners as stated by Chu et al. (2013). During the data collection process in the Fletcher et al. study, senior leadership staff and teachers at the site of research were present when students expressed their views. My research study purposefully excluded teachers from the talanoa process in the hope that it would alleviate potential anxiety students might feel over offending teachers, or feeling their contributions would affect important relationships. Although positive student/teacher relationships were identified as a factor supporting positive learning outcomes, it was the students' peers who offered the largest amount of support within the classroom. The findings showed that the students searched for times in the classroom when they were able to echo the structures that were in place in other parts of their lives, such as church, the home, and the team sports they played in. This means that student learning is not just enabled when students are provided explicit opportunities from teachers to exercise their preferred ways of learning, but that these students were actively and consciously finding ways to support themselves and their peers in learning.

\section{Filifiliga Sa'oloto}

The second major finding in this study was the concept of filifiliga sa'oloto, or the need for Samoan students to be able to express their own opinions without fear or pressure. The observations showed the students' reaction to bringing their own experiences into the classroom, and the discussion in talanoa revealed student awareness of their need to personally connect to the experiences of the English classroom. The literature describing what supports Pacific learners to succeed in mainstream classrooms indicates that classrooms that reflect the value system of the learner provide a better learning environment. Nakhid (2003) researched mainstream secondary school teachers' and Pacific students' perceptions of each other, and the often inaccurate reading teachers had of Pacific students and their parents. Nakhid's findings showed that the teachers in her study often attributed Pacific low achievement to cultural factors, such as parents' low expectations or engagement with school, or Pacific students' lack of motivation. Pacific students in the study expressed feelings that teachers held low expectations of them due to the way they spoke, dressed and interacted. This thesis supports Nakhid's findings that teachers did not often see Pacific students as working to their ability; more than this, the participants reported teachers' perceptions did not impact their feelings of 
their own ability. They were confident in their knowledge of support from aiga, and their ability to use their peers to fill gaps in their understanding of concepts or tasks. When the space was offered by teachers to take time with peers and discuss concepts in Samoan, or come to a common understanding of requirements, then they could successfully complete the requirements of the classroom.

In addition to teachers' perceptions of Pacific students' abilities, another barrier for Pacific learners identified by researchers and government reports is the difficulty for Pacific learners to succeed in an education system dominated by Western pedagogies. A key theme idea in the literature on Pacific students in English is that when there is a mismatch between students' culture and the value of the school system, this causes barriers to learning outcomes. The participants of this study acknowledged their desire to see themselves in the texts they studied, and were not oblivious to the fact they were not being represented in the texts that were studied in class; however, they also provided ways to combat this. The students felt heavily supported by their families, and found many opportunities to bring their culture into the classroom when they were given space to do this. The teachers who provided opportunity for autonomy and to operate agency when they designed tasks assisted in students' ability to express their identities in class. While the literature often called for teachers to provide the opportunities for students to use prior knowledge and their own experiences, the observations showed that the students were well aware of how to do this for themselves when space was given to them. Participants described clear differences between their English classes, which they felt usually provided opportunities to bring their own experiences into tasks, and other classes where tasks are inflexible and rigid. This could mean the difference between teaching a skill through a self-chosen topic, and teaching a skill through a teacher chosen topic.

The students reported that being able to offer their own interpretations of texts was a skill that came from a close connection with fa'asamoa, which literally translates to "the way of Samoa"; in this context it can be interpreted as the students feeling confident in their knowledge of the Samoan way of life. Instead of acting as a barrier, the ability to apply their own knowledge to texts formed a unique reading of texts, and when this was supported by teachers meant students were often analysing texts at a higher level than their New Zealand/European peers. One example of this is the deeper awareness the Samoan students expressed when describing metaphors. Being familiar with the heavily metaphorical nature of the Samoan language, as well as metaphors used in Biblical passages, the students felt comfortable in how they could bring these into their own 
writing. They were also often able to provide a sophisticated interpretation of metaphors given as examples in class.

A pervasive assumption of Pacific students is what is seen as behaviours of avoidance, a general reluctance to question authority or question texts, which is a requirement of the English curriculum (Ministry of Education, 2007). Dickie (2010) rejected this assumption, explaining that Bible literacy skills could be transferred to the classroom setting positively. The findings from Dickie's study suggest that the students are very comfortable with questioning and critiquing texts, and understand the difference between challenging the teaching of the Bible and close reading of texts - the reluctance to question comes from the atmosphere of the class. When students felt that from the beginning of the lesson to the end they were being misunderstood, they described feeling defeated, which resulted in zoning out and waiting to leave. Adding to Dickie's finding, not only did the skills developed in Sunday school act as a support, the participants were aware of this skill, and it was obvious in our talanoa that our discussion was not the first time they had become aware of the skills they possessed and that they brought into the English class from a different context. The students' conversations and prompts to each other during observations were often prefaced by "Remember? We have done this in Church", when they were finding language features in a speech or "Those verses are like in the Bible" when they were learning about poetry and stanzas. Not only are they aware of the skill, they are eager to use it and verbalise to each other how it works in English. The implication here is that providing space for Samoan students to bring in the skills they have already developed will not just help with learning outcomes, it develops metacognition and a sense of learner autonomy.

\section{Fa'atua}

The final theme from this study was fa'atua, which centres on positive relationships, and the importance of feeling heard. One of the clearest messages from the literature on Pacific learner success is the importance of strong positive relationships between Pacific students and teachers to improve learning outcomes. Much of the literature calls for awareness from teachers that Pacific students live in the 'siloed' worlds of home, school and church, and often want to keep these as separate as possible. Hawke and Hill (1998) discussed issues that Pacific and Māori students face when the value system that is operating in their lives outside of school and in school conflict, stating: 
try to deal with the conflicting pressures include "making excuses" i.e. telling lies, avoidance or opting out altogether. (1998, p. 2)

The participants in my study, however, seem to be actively looking for places that would allow them to bring their home world into the life of the classroom. Participants reported opting for speaking about their family or traditions and culture most often when they were able to choose the theme they wrote on in English. Contradictory to Hawke and Hill, the students did not want to separate the complex worlds they inhabited and often used their strong knowledge of their 'Samoan world' to inform their 'school world'. An example of this was during one observation a group of Samoan participants understood one of the school proverbs Whaia te iti kahurangi ki tuohu koe me he maunga teitei, which translates to: "Seek the treasure you value most dearly: if you bow your head, let it be to a lofty mountain." The whakatauki was referred to by the teacher as an example of metaphor and the Samoan students explained what the meaning of the proverb was, explaining to the teacher and other non-Samoan group members that there are many proverbs like this one in Samoan. Reflecting on this during the talanoa, the students explained they were very accustomed to metaphorical language and felt confident sharing their knowledge in class. This is an illustration of the students not only being proud of the world they are from but keenly using it to support them in class.

My study is aligned with the findings of Siope (2011) and Mila-Schaaf and Robinson (2010), who although supporting the findings of Hawke and Hill that describe Pacific students wanting to keep the many worlds they inhabit as separate (2002), offered a more developed idea of Pacific students and the implications of poor or positive relationships with teachers. Siope offered Pacific students perspectives on how they experienced learning in secondary school as a comparison to her experience in the 1980s. One of the findings from Siope's study was how important it is for teachers to be secure in their own cultural knowledge. The impact of teachers who are not aware of their own and other people's cultures on Pacific students is Pacific students wanting to be invisible in class. The Samoan students in my study described their experiences of being in classes where they felt the teacher was unaware of their culture; this is in line with the students in Siope's study. The participants in my study reported a difference, however, from wanting to be invisible, and explained they often wanted to speak out, they were willing to be visible and explain their culture, traditions, myths and legends, and were also willing to verbalise their preferred ways of learning but only if provided space to do so. Our conversations during the talanoa process did not seem to centre on wanting to blend in and become invisible or, as Siope states, "live in "siloed" worlds in which their school, 
family and church lives are kept separate". The participants in my study seemed to want to be less invisible, and described being frustrated, disappointed, fed up and angry when their attempts to bring their culture into the classroom were disregarded. The students in this study reported being unlikely to engage in a class where they felt their culture was unfairly represented. They also expressed feeling more confident, attempting new tasks when they were able to draw on knowledge that came from their own culture. The participants were enthusiastic about showing their knowledge of the other worlds they operated in when the teacher provided a safe space to do so.

Much of the government literature providing information about Samoan students is not ethnic specific, but rather under the Pacific or 'Pasifika' umbrella, in spite of strong recommendations that researchers recognise this group as heterogeneous (Anae et al., 2001). Literature commissioned by the government provides strategies (1990s-2013), such as making learning relevant for the learners, using group work, and developing strong positive relationships between student and teacher. Developing these themes, which have been articulated in many ways over the past two decades, the participants in this research study were able to articulate why specific strategies are effective and add to teachers' understanding of exactly what is happening in their classes by providing details of thought processes during interactions. They were able to describe that to successfully navigate the English classroom they relied on friends re-wording assessment tasks or new information, and they brought in knowledge from outside the English classroom such as the ability to memorise texts and an awareness (through their knowledge of the Bible), or the importance of reading comprehension to gain the most meaning they can from a text. They articulated how they operated outside of class and why then it was natural to try to succeed as a collective in class and speak about the high expectation they placed on themselves, and the support they felt from their families. The participants had a strong understanding of not only what worked best for them, but why strategies such as group work supported achievement.

\section{Implications for Teaching}

While it is important for teachers of Pacific students to understand the potential of their Pacific students, there is an assumption that this awareness is needed because the students themselves are unaware of their potential. The students in this study often articulated high expectations they placed on themselves and felt these high expectations were sometimes not matched by the teachers. They explained strengths like leadership and caring for each other, the ability to organise each other and regulate whether their 
peers were trying hard enough, yet said these were either overlooked or turned into a negative by some teachers. The students were well aware of where they needed help and were often self-managing in class when they were allowed to be. In all the English observations the students had a well-practised process that they were given the space by the teacher to operate.

\section{Recommendations for Teachers}

The following section provides some specific recommendations; however, there is a deeper understanding that emerges throughout the research that teachers need to be acting as ethnographers, observing deliberate choices the students are making and trusting the student that their choice is the best approach to learning for them. By observing Pacific students from the students' point of view and giving over trust, English teachers can allow these students to make decisions for themselves about their learning, which will give students a sense of ownership, both over the learning and English as a subject.

During the observations positive learning outcomes were happening when teachers were stepping far enough back to allow the participants to self-organise into learning groups, and monitor and correct each other. When teachers were allowing students to navigate tasks in this way, and paying close attention to the choices the students were making, teachers then were able to make deliberate choices in planning to provide further opportunities for the way the student had chosen to complete the task.

If teachers can tune in to what the students can already do and seek to understand that the choices being made by students are part of the navigating process then the suggestions below will already be happening.

The 2004 teacher census from Education Counts reports 2\% of secondary teachers identifying their first ethnicity as 'Pasifika', while Quickstats New Zealand reports Pacific peoples as the ethnicity with the highest proportion of children of any ethnic group in New Zealand (35.7\% of the population between the ages of 0 - and 14). The implication of this is that most teachers will experience teaching students who are not sure of their ethnic background, and most Samoan students will not be taught by Samoan teachers. With this in mind teachers need to stand back and take cues from the students who have already figured out the best way for them to learn, and facilitate ways that allow students to positively deviate from what is reported in learning outcomes in national data. In this way positive deviation is not about the teacher making learning happen, it is about letting 
learning happen. The teacher sets the learning process in motion and steps back to allow Pacific students to self-organise, and use the navigational tools that best suit the task.

One consideration when using Mila's concept of Polycultural capital as a framework to understand this research is that often in the data collection process the three students who reported relating the least to fa'asamoa (or Samoan ways of being) were also the least vocal about using 'capital' they had learned in Samoan contexts as helpful to them when navigating English. However, despite these three second generation Samoan students not reporting using Polycultural capital to gain positive learning outcomes in the English class, they did take obvious cues from the other participants when attempting tasks. The three participants reported in follow-up talanoa that they would look to the others for help to unpack tasks, and gained confidence from working in groups together.

While reluctant to provide a tick box for better serving Samoan students in the English classroom, the observations in English classes and the talanoa that emerged in the data collection process suggest the following are important considerations for teachers:

- Be self-critical: Even teachers who share the ethnic background of the students they teach are from a different generation. If teachers are seeking to understand Samoan student choices it will involve constant self-reflection about the environment the student is trying to navigate, and assumptions teachers know how their students are learning best. To tune-in to these students it means questioning our own assumptions behind what is best and taking our cues from the students. This is the basis of fa'atua, creating a space where everyone's opinions are regarded with importance and filifiliga sa'oloto, which is the freedom for the students to express their opinions without fear.

- Take a step back: If teachers place student choice at the centre of the classroom, and trust that the student can navigate tasks autonomously, then it allows the teacher more time to observe. Teachers can focus on setting tasks up, then stepping back to allow self-organisation or felagolagoma'i, allowing students to work with each other and for each other towards a common goal.

- Be brave: To allow felagolagoma'i to take place teachers need to be brave and trust that although the process of self-organisation may look messy, the students are capable of far greater interdependent learning when they are given the opportunity. In order for teachers to acknowledge the knowledge that already exists in the classroom 
they must trust the students to find the best way to access and apply knowledge they already possess to new tasks. This develops fa'atua in a classroom, positive, meaningful, respectful and reciprocal relationships, which will in turn encourage students to take risks when learning.

A key finding from this research is that the students are holding the skills needed for positive learning outcomes in the English classroom, and when safe spaces are provided by teachers for the students to self-organise and access these skills, Samoan students are successfully navigating English.

Throughout the research process I often thought back on a statement Mareko made while speaking about advice he would give teachers who have Pacific students in their classes. This offering was “Don't slow me down”, like the Samoan proverb: Ia fili e le tai se agava ' $a$, which translates to "let the wind choose as to the quickness of a canoe". Shana Muiava, a good friend, explained the proverb as relating to the knowledge of our seas, used by Samoans when wanting to select an experienced orator to speak on an occasion. The sea will choose the experienced. It means that in times when experience is needed, it is best to leave it to those with knowledge and expertise. When used in an education context, one interpretation is that educators need to assess the skills and knowledge they hold, and the skills and knowledge that Pacific students hold, and then allow those with more expertise to take the lead. In the case of the Samoan students in this study, when teachers stepped back and let the students be the experts of their own knowledge, positive learning outcomes happened. This advice to teachers from one group at least of their students is to step back and allow Samoan students to navigate their course, at a pace they choose, utilising tools they choose. This study makes a case that the pace they choose may be faster than expected. 


\section{References}

Allen, P., \& Robertson, J. (2009). 'In order to teach you, I must know you:' The Pasifika initiative: A professional development project for teachers. New Zealand Journal of Educational Studies, 44(2), 47.

Alton-Lee, A. (2003). Quality teaching for diverse students in schooling: Best evidence synthesis. Wellington, NZ: Ministry of Education.

Anae, M., Coxon, E., Mara, D., Wendt-Samu, T., \& Finau, C. (2001). Pasifika education research guidelines: Final report. Wellington, NZ: Ministry of Education.

Anae, M., Mila-Schaaf, K., Coxon, E., Mara, D., \& Sanga, K. (2010). Teu Le Va-Relationships across research and policy in Pasifika education: A collective approach to knowledge generation \& policy development for action towards Pasifika education success. Wellington, NZ: Ministry of Education.

Airini, Brown, D., Curtis, E., Johnson, O., Luatua, F., O’Shea, M., ... Ulugia- Pua, M. (2010). Success for all: Improving Mäori and Pasifi ka learner success in degree- level studies. Retrieved from http:// www.tlri.org.nz/sites/default/fi les/projects/9247- Airini- fi nalreport.pdf

Banks, J. A., Cookson, P., Gay, G., Hawley, W. D., Jordan Irvine, J., Nieto, S. ... Stephan, W. G. (2001). Diversity within unity: Essential principles for teaching and learning in a multicultural society. Seattle, WA: Center for Multicultural Education, School of Education, University of Washington. doi.org/10.1177/003172170108300309

Berggren, W. L., \& Wray, J. D. (2002). Positive deviant behavior and nutrition education. Food Nutr Bull, 23(4 Suppl), 7-8. doi.org/10.1177/15648265020234S202

Bourdieu, P. (2007). The forms of capital. In A. R. Sadonik (Ed.), Sociology of education (pp. 83-95). New York: Routledge.

Brayboy, B., \& Castagno, A. (2008). Culturally responsive schooling for indigenous youth. Review of Educational Research, 78(4), 941-993.

Burrell, G., \& Morgan, G. (1979). Sociological paradigms and organisational analysis. London: Heineman Educational Books.

Chu, C. M. (2009). Mentoring for leadership in Pacific education.(Unpublished doctoral thesis). Victoria University of Wellington, New Zealand

Chu, C., Glasgow, A., Rimoni, F., Hodis, M., \& Meyer, L. (2013). An analysis of recent Pasifika education research literature to inform improved outcomes for Pasifika learners. Wellington, NZ: Jessie Hetherington Centre for Educational Research, Victoria University of Wellington.

Creswell, J. W. (2003). Research design: Qualitative, quantitative, and mixed methods approaches. Thousand Oaks, CA: Sage 
Coxon, E., Anae, M., Mara, D., Wendt-Samu, T., \& Finau, C. (2002). Literature review on Pacific education issues. Auckland, NZ: University of Auckland.

Dickie, J. (2011). Samoan students documenting their out-of-school literacies: An insider view of conflicting values. Australian Journal of Language and Literacy, 34(3), 247-259.

Edwards, S. (2014). Supporting English language learners: New Zealand secondary mainstream teachers' knowledge and use of recommended teaching resources and strategies. New Zealand Journal of Educational Studies, 49(1), 43-58.

ERO. (2009). Progress in Pacific student achievement: A pilot evaluation of Auckland schools.

Retrieved from http://www.ero.govt.nz/National-Reports/Progress-in-Pacific-StudentAchievement-A-pilot-evaluation-of-Auckland-schools-September-2009

ERO. (2010). Promoting student achievement: Schools' progress. Retrieved from http://www.ero.govt.nz/National-Reports/Promoting-Pacific-Student-Achievement-June2010

ERO. (2012). Improving education outcomes for Pacific learners. Retrieved from http://www.ero.govt.nz/National-Reports/Improving-Education-Outcomes-for-PacificLearners-May-2012

ERO. (2013). Making connections for Pacific learners' success. Retrieved from http://www.ero.govt.nz/National-Reports/Making-Connections-for-Pacific-LearnersSuccess-November-2013

Farrelly, T., \& Nabobo-Baba, U. (2012, December). Talanoa as Empathic Research. Paper for presentation at the International Development Conference 2012 Auckland, New Zealand.

Farrelly, T., \& Nabobo-Baba, U. (2014). Talanoa as empathic apprenticeship. Asia Pacific Viewpoint, 55(3), 319-330. doi.org/10.1111/apv.12060

Ferguson, P. B., Gorinski, R., Samu, T. W., \& Mara, D. L. (2008). Literature review on the experiences of Pasifika learners in the classroom. Wellington, NZ: Ministry of Education.

Fletcher, J., Parkhill, F., Fa'afoi, A., \& O'Regan, B. (2009). Pasifika students: Teachers and parents voice their perceptions of what provides supports and barriers to Pasifika students' achievement in literacy and learning. Teaching and Teacher Education, 25(1), 24-33. doi.org/10.1016/j.tate.2008.06.002

Fletcher, J., Parkhill, F., \& Fa'afoi, A. (2005). What factors promote and support Pasifika students in reading and writing. SET: Research information for teachers, (2), 2-8.

Fletcher, J., Parkhill, F., Fa'afoi, A., \& Taleni, L. T. (2008). Influences on Pasifika students' achievement in literacy. SET: Research information for teachers, (1), 4-9.

Fletcher, J., Parkhill, F., \& Harris, C. (2011). Supporting young adolescent students from minority cultural groups who are underachieving in learning. Support for Learning, 26(3), 122-126. doi.org/10.1111/j.1467-9604.2011.01490.x 
Gay, G. (2002). Preparing for culturally responsive teaching. (2001 AACTE Outstanding Writing Award Recipient). Journal of Teacher Education, 53(2), 106. doi.org/10.1177/0022487102053002003

Gorinski, R., \& Fraser, C. (2006). Literature review on the effective engagement of Pasifika parents and communities in education. Wellington, NZ: Research Division, Ministry of Education.

Hawk, K., Cowley, E. T., Hill, J., \& Sutherland, S. (2002). The importance of the teacher/student relationship for Māori and Pasifika students. Set: Research Information for Teachers, 3, 44-49.

Hill, J., \& Hawk, K. (1998). Aiming for student achievement: How teachers can understand and better meet the needs of Pacific Island and Māori students. SET: Research Information for Teachers, 2. Item 4.

Hynds, A., \& McDonald, L. (2010). Motivating teachers to improve learning for culturally diverse students in New Zealand: Promoting Māori and Pacific Islands student achievement. Professional Development in Education, 36(3), 525-540. doi.org/10.1080/19415250903319275

Johnson, B., \& Christensen, L. (2012). Educational research: Quantitative, qualitative, and mixed approaches. Los Angeles, CA: SAGE.

Klein, H. K., \& Myers M. D. (1999). A set of principles for conducting and evaluating interpretive field studies in information systems. MIS Quarterly, 23(1), 67-94.

Lai, M., McNaughton, S., Hsiao, S., Mose, K., Hall, A., Knight, N., \& Gray, C. (2010). Sustaining improvements in student achievement,'myth or reality'?Set: Research information for teachers, (1), 10-17.

Marsh, D. R., Schroeder, D. G., Dearden, K. A., Sternin, J., \& Sternin, M. (2004). The power of positive deviance. BMJ, 329(7475), 1177-1179. doi.org/10.1136/bmj.329.7475.1177

McNaughton, S., \& Lai, M. K. (2009). A model of school change for culturally and linguistically diverse students in New Zealand: A summary and evidence from systematic replication. Teaching Education, 20(1), 55-75. doi.org/10.1080/10476210802681733

Mila-Schaaf, K. (2010). Polycultural capital and the Pasifika second generation: Negotiating identities in diasporic places (Unpublished doctoral diss.). Massey University, Albany, NZ.

Mila-Schaaf, K., \& Robinson, E. (2010). Polycultural'capital and educational achievement among NZ-born Pacific peoples. Mai review, 1, 1-18.

Ministry of Education. (2006). Pasifika education plan: Monitoring report. Wellington, NZ: Ministry of Education.

Ministry of Education. (2007). The New Zealand curriculum. Wellington, NZ: Learning Media. Ministry of Education. (2009). Ua aoina le manogi o le lolo Pasifika schooling improvement research: Final report. Wellington, NZ: Ministry of Education. 
Ministry of Education. (2010). The Pasifika education plan: Monitoring report. Wellington, NZ: Ministry of Education.

Ministry of Education. (2011). Tãtaiako: Cultural competencies for teachers of Māori learners. Wellington, NZ: Ministry of Education.

Ministry of Education. (2012a). Pasifika education plan 2013-2017. Wellington, NZ: Ministry of Education.

Ministry of Education. (2012b). Pasifika education research priorities using research to realise our vision for Pasifika learners. Wellington, NZ: Research \& Evaluation Team, Ministry of Education.

Ministry of Education. (2013). Pasifika education plan monitoring report: 2013. Wellinton, NZ: Ministry of Education.

Nakhid, C. (2003). "Intercultural" perceptions, academic achievement, and the identifying process of Pacific Islands students in New Zealand schools. Journal of Negro Education, 72(3), 297-317. doi.org/10.2307/3211249

Quickstats, N. Z. (2013). 2013 census quickstats about culture and identity. Retrieved from http://www.stats.govt.nz/Census/2013-census/profile-and-summary-reports/quickstatsculture-identity/pacific-peoples.aspx

Robertson, K. (2013). Ensuring literacy aquisition for adolescent Pasifika. Kairaranga, 14(2), 4046.

Robinson, V. (2000). Reducing differential educational attainment: Have we really tried? Improving Schools, 3(1), 40-44. doi.org/10.1177/136548020000300107

Robinson, V. M., Timperley, H., Ward, L., Tuioti, L., Tu'uga Stevenson, V., \& Mitchell, S. (2004). Strengthening education in Mangere and Otara evaluation: Final evaluation report. Wellington, NZ: Ministry of Education.

Rowlands, B.H. (2005). Grounded in practice: using interpretive research to build theory. Electronic Journal of Business Research Methods, 3(1), 81-92.

Samu, T. W. (2006). The 'Pasifika umbrella' and quality teaching: Understanding and responding to the diverse realities within. Waikato Journal of Education, 12, 35-49.

Savage, C., Hindle, R., Meyer, L. H., Hynds, A., Penetito, W., \& Sleeter, C. E. (2011). Culturally responsive pedagogies in the classroom: Indigenous student experiences across the curriculum. Asia-Pacific Journal of Teacher Education, 39(3), 183-198. doi.org/10.1080/1359866X.2011.588311

Siope, A. (2011). The schooling experiences of Pasifika students. Set:Reseach information for teachers, (3), 10-16.

Sleeter, C. E. (2011). An agenda to strengthen culturally responsive pedagogy. English Teaching: Practice \& Critique, 10(2), 7-23.

Smith, L. T. (2012). Decolonizing methodologies: research and indigenous peoples (2nd ed.). London: Zed Books. 
Spiller, L. (2012). How can we teach them when they won't listen: How teacher beliefs about Pasifika values and Pasifika ways of learning affect student behaviour and achievement. Set: Research Information for Teachers, 3, 58-66.

Sturrock, F. M. (2004). Focus on Pasifika achievement in reading literacy: Results from PISA 2000. Wellington, NZ: Comparative Education Research Unit, Research Division, Ministry of Education.

Suaalii-Sauni, T., \& Fulu-Aiolupotea, S. M. (2014). Decolonising Pacific research, building Pacific research communities and developing Pacific research tools: The case of the talanoa and the faafaletui in Samoa. Asia Pacific Viewpoint, 55(3), 331-344. doi.org/10.1111/apv.12061

Taleni, T., Parkhill, F., Fa'afoi, A., \& Fletcher, J. (2007). Pasifika Students: What supports them to become better readers? Pacific-Asian Education Journal, 19(2). 64-82.

Vaioleti, T. M. (2006). Talanoa research methodology: A developing position on Pacific research. Waikato Journal of Education, 12, 21-36.

Yin, R. K. (1994). Discovering the future of the case study method in evaluation research. Evaluation Practice, 15, 283-290. 


\section{Appendix}

\section{Student Consent Form}

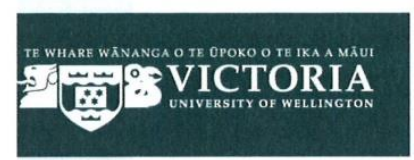

SCHOOL OF EDUCATION TE PUNA AKOPAI

FACULTY OF EDUCATION TE WHĀNAU O AKO PAI

VICTORIA UNIVERSITY OF WELLINGTON, PO Box 17-310, Donald St, Karori, Wellington 6147, New Zealand Phone +64-4-4639500 Fax +64-4-4639649 Email education@vuw.ac.nz Web www.victoria.ac.nz/education

\section{Student Consent Form}

Research Project on Exploring how Year 10 Samoan students navigate teaching and learning in the English classroom.

- I have read letter and understand what will happen if I agree to be in the study.

- I agree to participate in talanoa (informal focus groups) and one-on-one interviews and I know they will be recorded.

- I know that I can decide that I do not want to be part of the study at any time before early November 2015 - if I do this I know nothing I have said will be used.

- I know that any information I give will not be used to tell who I am, what school I go to, or any other person in the study. I also know Kalia Lautusi, her supervisors and the person who transcribes the discussions will be the only ones who hear the recordings.

- I know that what I say will be shown to me and I will check if I agree with what the researcher has said.

- I understand that after the project is complete, all notes of my talanoa session and interviews will be destroyed.

- I understand that my responses may be used in papers or presentations that are concerned with Pacific Island learners in English.

* If you have read, understood and agree to ALL points listed above tick the correct box below.

Please be aware participants are able to withdraw from the study at any time before the end of the data collection phase. No reason will need to be provided for withdrawing.

I agree to participate in this research

I do not agree to participate in this research

If you wish to receive a summary of the results by email, please check this box If you wish to receive a printed summary of the results please check this box

Please sign and date reverse side of this consent form. 
Email address:

Student's Name:

Student's Signature:

Date:

Please complete this form and return it to me [date] 2015. 


\section{Student Information Sheet - English}

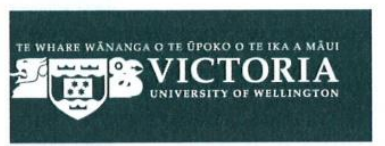

SCHOOL OF EDUCATION TE PUNA AKOPA

FACULTY OF EDUCATION TE WHĀNAU O AKO PAI

VICTORIA UNIVERSITY OF WELLINGTON, PO Box 17-310, Donald St, Karori, Wellington 6147, New Zealand

Phone +64-4-4639500 Fax +64-4-4639649 Email education@vuw.ac.nz Web www.victoria.ac.nz/education

\section{Student Information Sheet \\ Research Project: Exploring how Year 10 Samoan students navigate teaching and learning in the English classroom.}

Talofa lava,

My name is Kalia Lautusi, and as you may be aware I am an English teacher at Naenae College. This year I have taken a year off to study at Victoria University. I am writing this letter to invite you to be part of a study I am doing. The study is to help educators better understand what the strengths and skills are that Samoan students and their families know about - and how these students use their skills in English.

The goals of the study are:

1. To better understand the strengths and skills Samoan students bring with them to the classroom.

2. To better understand what Samoan students are thinking during different parts of English classes.

3. To better understand which parts of English classes Samoan students find the most fun, and which parts they find most frustrating.

As part of the research I would like to invite you to join in with three focus groups (one in each remaining term of the school year), where you will talk about your strengths and skills and how you use these in the English classroom. You will also be asked to talk about how your family supports you to do well and things that are helpful, and not so helpful in the English classroom.

There will be three Samoan students in each focus group and these will last for about 3060 mins. With your parents' permission, I will run these focus groups at a time that is good for the teacher, or during a free time for you. You will not miss any important class time. I would love to hear about your experiences in English and learn more about the skills you bring with you to the English classroom.

After the focus group I will also ask to interview you by yourself after I have watched an English class. This interview will be about what parts of the lesson you enjoyed and what you were thinking at different parts of the lesson, this will take 20-30mins. Both the focus group and the interview will be recorded. These will also be transcribed, should a transcriber be used to write down the recordings, they will have to sign an agreement that says they cannot share any information they have heard. All recordings will be kept safe so it can only be seen or heard by me and my two Victoria University advisors, Dr Gillian Hubbard and Dr Cherie Chu. All recordings will be deleted after the project is finished. I will change your name in anything I write so no one can identify you. 
At the end of the focus groups and interviews I will share what I think your main points were with you - to check I have properly understood what you tell me. In order to respect the views of others and maintain confidentiality wherever possible, please keep everything discussed within the focus group to yourself. If I am your English teacher in 2016, when I return, I will make sure that nothing you have told me in these talanoa or interviews, will negatively affect our relationship or your achievement in our class.

Participation is voluntary, which means you do not have to take part in this study and you can stop being in the study at any time before early November 2015. If you stop being in this project I will not use anything you have said in any part of the study. You will not have to have any reason for withdrawing.

The findings of this study will be published in my thesis and may also be used to make presentations at conferences of educators, and write papers for publication in academic journals in order to help teachers of Samoan students improve their craft. You will not be identified by name in any presentation or report. I will not use the recordings at any presentation. Naenae College will also not be named in any presentation. If you want a copy of the main points of the study please tick the correct box on the consent form.

If you are happy to participate your parent or caregiver must sign the parent/caregiver consent forms attached, and you should sign them too, as well as the student consent form. All forms are available in both English and Samoan, if you wish to read a Samoan translation of this letter, or you have any questions at all, please feel free to email me at if you want to contact my supervisors their email addresses are Cherie.chu@vuw.ac.nz and Gillian.hubbard@vuw.ac.nz.

Please note: this research has ethical approval from the VUW Faculty of Education Ethics Committee. Should you have any ethical concerns please contact Dr Allison Kirkman, Chair of the Human Ethics Committtee. Allison.kirkman@vuw.ac.nz Ph: 044635676.

Kind regards,

Kalia Lautusi 


\section{Student Information Sheet - Samoan}

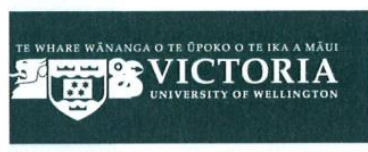

SCHOOL OF EDUCATION TE PUNA AKOPA

FACULTY OF EDUCATION TE WHĀNAU O AKO PAI

VICTORIA UNIVERSITY OF WELLINGTON, PO Box 17-310, Donald St, Karori, Wellington 6147, New Zealand

Phone +64-4-4639500 Fax +64-4-4639649 Email education@vuw.ac.nz Web www.victoria.ac.nz/education

\section{Student Information Sheet \\ Research Project: Exploring how Year 10 Samoan students navigate teaching and learning in the English classroom.}

Talofa lau susuga i le tamaitai/ alii aoga,

O lou igoa o Kalia Lautusi, e pei ona outou silafia o au o le faiaoga i le mataupu o le gagana peretania i le kolisi o Naenae. I le taimi nei o loo ave a'u suesuega mo le tausaga 2015, aua ni manatu faaalia i suesuega faaaliga manatu (thesis) i le Iunivesite o Vitoria, Ueligitone. O le manulauti o lenei laupepa e fai ma tusi valaau i lau susuga e manaomia lou fesoasoani mai $\mathrm{i}$ lenei suesuega o le a ou saunia e faatino. O lenei suesuega e faasino lea i le malamalama'aga o tama ma teine aoga Samoa ma o latou aiga ona vaevaeina ma faaalia o latou atamai ma agatausili, ma pe faapefea ona latou faaaogaina ma asa ina le gagana peretania $\mathrm{i}$ totonu o vasega.

O le manulauti o suesuega:

1. Ia lelei ona malamalama le malosi ma le atamai o Tamaiti Samoa i totonu o le vasega.

2. Ia malamalama lelei taiala e tamaiti Samoa e faaaoga auala ma aiaiga i le faaaoga ina o le gagana i totonu o le vasega

3. Oa ni vaega o le polokalame o le gagana peretania o loo faogaina e tamaiti Samoa o loo latou auai iai, ma nisi o vaega o loo fai ma faafitauli ia latou.

O se vaega o lenei suesuega, oute valaauina lau susuga, ina ia e auai ma a'u nei i ni vaega faapitoa e tolu (e taitasi mai o le vai- tuuaga mulimuli o le aoga), i lea itu e mafai ai ona faailoa lou malosiaga ma lou tomai i le faaaogaina o le gagana Peretania i totonu o le vasega. $\mathrm{O}$ le a fesiligia foi oe pe faapefea ona fesoasoani lou aiga ina ia taunuu lou faamoemoe atoa ai ni vaega e fesoasoani tele, faapea foi le atoa o fesoasoani i le gagana peretania i totonu o le vasega. E toatolu tamaiti aoga Samoa mai vaega faapitoa nei, mo le 30-60 minute. I le faatagana mai i ou matua, ole a ou avea nei vaega faapitoa i taimi talafeagai ai ma le faiaoga, poo taimi foi o e avanoa ai, e te le misi ina ni feau e tusa ai ma ou taimi tusia. E fiafia foi e faalogo atu i lou tomai i le gagana peretania ma faaauau pea aoaoga e tusa ai ma ou tomai ua e aumai i le vasega o le gagana peretania

Mulimuli mai i lenei vaega faapitoa, ua iai se manatu ia te a'u e fesiligia ai lau susuga i le mae'a ai lea ma lo'u mata'ituina o le vasega o le gagana faaperetania. O lenei faatalatalanoaga e patino tonu i vaega o le lesona sa e fiafia iai, atoa ai ma ni ou manatu i tulaga eseese o piriota o nei lesona, mo le 20 ile 30 minute. $O$ nei vaega faapitoa e mafai ona ou talosaga ina faatalatalanoa oe, e faaleoina lona pu'eina, faamauina. $\mathrm{O}$ le a mafai foi ona tusitusiina, a talafeagai lea itu, e tatau ma onomea le saini ina se maliega faalilolilo faapitoa. O faamatalaga uma ua tuuina mai o le a teuina ia faila i se upu 
tusia(password) e mafai ai ona puipuia faamatalaga, vagana lava na o a'u oute puipuia ma vaai iai faatasi ai ma au fautua e toalua o le Univesite i Vitoria o Dr Gillian Hubbard ma Dr. Cherie Chu, o nei faamaumauga uma a uma loa le poloketi, ona faaleaogaina loa lea. O le a le mafai ona toe iloa ina ia faamaumauga, poo ai oe sa auai, ona o le a mafai ona ou suia igoa ma mea uma tau I ia faamaumauga sa ou faia. Ma oute pupui foi ou aia tatau. I le faaiuga o nei vaaega faapitoa ma le faatalatalanoaina, o le a mafai ona ou tuufaatasi ina faamaumauga aoga ma patino tonu iai lenei suesuega, ma fasoa ma oe aua se sao ma vaai lelei i mea ua manino ma malamalama iai e pei ona faamalamalama.

O lou auai e saoloto, ma e ia te oe le aia tatau e mafai ai ona toe faaalia lou le fia auai i soo se taimi ae lei mae'a le tuuina faatasi o mea ua uma ua tuuina mai, e faagata ia Novema 2015. E leai foi se fesili pe aisea ua e faamaamulu ai.

O le mae'a ai o lenei suesuega, o le a lolomiina ou mafaufauga (thesis) ma e ono mafai ona faaaogaina i ni fonotaga a nisi o le tomai faafaiaoga, tusia ni pepa faamatalaga mo niusipepa i tulaga faa leaoaoga poo tala pupuu, e mafai ona maua se fesoasoani i faiaoga mo tamaiti Samoa aua le alualu i luma o o latou faatufugaga. E le mafai foi ona faailoaina oe i lou igoa poo nisi faamatalaga po'o se ripoti. E le mafai ona ou faaaoga ina ni puega leo I nei faamaumauga. E le mafai foi ona faailoa lau aoga ma lona aigoa I ney

faamaumauga. A fai ete finagalo I sau kopi o lenei suesuega, faamolemomle faailoa mai I le togi ina o le pusa o le loto malie.

Afai ua faamalieina oe I lou auai, e tatau ona faamaonia lea tulaga I le saini mai o ou matua poo se tasi foi o loo vaai faletulafono ina oe, i le pepa ua faamlieina ua tuuina atu, e alagatatau foi ona e saini iai, faapena foi le pepa mo tamaiti aoga e taua o le "consent form'. O nei pepa uma o loo maua i le gagana peretania ma le gagana Samoa, a e fia vaai i le pepa ua uma ona faaliliuina mo tamaiti aoga, pe iai foi ni au fesili, e mafai ona emeli mai ia : Afai foi ete finagalo e faafesoo tai nisi o o'u taitai o i laua nei : o Cherie chu@vuw.ac.nz.and Gillian Hubbard@vuw.ac.nz.

Ma lo'u faaaloalo, o lenei suesuega ua iai le maliega tausili mai i le VUW Faculty of Education Ethics Committee. (komiti tau pulega o Aoaoga a le Iunivesite o Vitoria i Ueligitone) afai foi o iai se mataupu "tau tele" e tusa ai ma lenei tusi, faamolemole faafesootai Dr.Allison Kirkman,Chair of the Human Ethics Committee (o le faauluuluga ole komiti Tau Tagata Soifua ma Aga). Allisonkirkman@vuw.ac.nz.Ph:044635676

Ma lo'u faaaloalo lava.

Kalia Lautusi. 


\section{Parent Consent Form}

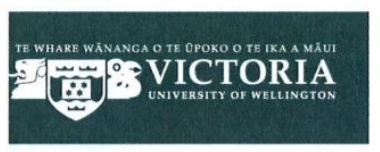

SCHOOL OF EDUCATION TE PUNA AKOPAI

FACULTY OF EDUCATION TE WHĀNAU O AKO PAI

VICTORIA UNIVERSITY OF WELLINGTON, PO Box 17-310, Donald St, Karori, Wellington 6147, New Zealand Phone +64-4-4639500 Fax +64-4-4639649 Email education@vuw.ac.nz Web www.victoria.ac.nz/education

\section{Parent Consent Form}

Research Project: Exploring how Year 10 Samoan students navigate teaching and learning in the English classroom.

- I have read information sheet and I understand what is involved in this study.

- I agree to my child participating in three talanoa sessions and follow up individual interviews.

- I understand that I my child may withdraw from the study at any time until the completion of the data gathering process in early November 2015.

- I understand that my child will not be able to be identified in the reports of the study.

- I understand that I will be invited to a talanoa session to discuss the themes identified at the end of the research process.

- I understand that after the project is completed all notes of all talanoa sessions and audio recordings will be destroyed.

* If you have read, understood and agree to ALL points listed above tick the correct box below. Please be aware participants are able to withdraw from the study at any time before the end of the data collection phase. No reason will need to be provided for withdrawing.

I give my consent for my child to participate in this research

I do not give consent for my child to participate in this research

If you wish to receive a summary of the results by email, please check this box If you wish to receive a printed summary of the results please check this box

Student's Name:

Student's Signature:

Parent's Signature:

Date: 


\section{Parent/Caregiver Information Sheet - English}

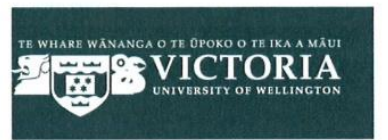

SCHOOL OF EDUCATION TE PUNA AKOPAI

FACULTY OF EDUCATION TE WHĀNAU O AKO PAI

VICTORIA UNIVERSITY OF WELLINGTON, PO Box 17-310, Donald St, Karori, Wellington 6147, New Zealand Phone +64-4-4639500 Fax +64-4-4639649 Email education@vuw.ac.nz Web www.victoria.ac.nz/education

\section{Parent/caregiver Information Sheet \\ Research Project: Exploring how Year 10 Samoan students navigate teaching and learning in the English classroom.}

Talofa lava,

As you may be aware I am an English teacher at Naenae College, currently on study leave for 2015 completing my Master's thesis. Following our talanoa session earlier this term, this is a formal request for permission for your child to participate in my research project. The research is aimed at understanding how Samoan students and their families perceive their own strengths and skills, and how these are used to navigate the English classroom.

The objectives of the study are:

1. To better understand the strengths and skills Samoan students bring with them to the classroom.

2. To better understand the strategies Samoan students use when navigating instructions and learning tasks in the English classroom.

3. To better understand which parts of the English programme Samoan students find the most engaging, and which parts they find most frustrating.

With your consent your child would participate with me in three focus groups (one in each remaining term of the school year), where they will discuss their strengths and skills and how they are used in the English classroom. They will also be asked to talk about how family acts as a support and what they find helpful and unhelpful in the English classroom.

There will be three Samoan students per focus group and these will last for about 3060 mins. With your permission, I will run these focus groups at a time that is convenient for the teacher, or during a free time for your child, they will not miss any direct instruction time.

After the focus group I will also ask to interview your child individually after I have observed an English class. This interview will be focussed on what parts of the lesson they enjoyed and what they were thinking at different periods in the lesson, this will take 20$30 \mathrm{mins}$. Both the focus group and the interview will be audio-recorded. These will also be transcribed. Should a transcriber be used in the processing of the recordings, they will be required to sign a confidentiality agreement. All electronic information will be kept in a password-protected file and will be restricted to me and my two Victoria University advisors, Dr Gillian Hubbard and Dr Cherie Chu. All recordings will be deleted after the project is complete. No recorded information will identify who they are, as I will change 
names in anything I write to protect participants' privacy. Participation or nonparticipation will not affect their academic progress in any way.

Participation is voluntary and students will have the right to withdraw at any time before the end of the data collection time, which will be early November 2015. They will not be required to provide any reason for withdrawing. As a teacher of Samoan ethnicity I understand the high value Samoan parents place on the importance of education, and the willingness to work alongside teachers to support academic achievement. It is with this in mind that I want to be sure that you as a parent feel no pressure to grant permission for your child to participate, and feel comfortable asking me to clarify any questions you may have. If you do have any questions at all, you can contact me via email at

$$
\text { or phone }
$$

The findings of this study will be published in my thesis and may also be used to make presentations at conferences of educators, and write papers for publication in academic journals in order to help teachers of Samoan students improve their craft. Your child will not be identified by name in any presentation or report. I will not use the audio recordings at any such presentation. Naenae College will also not be identified by name in any presentation.

Should you wish to receive a copy of the main findings, please indicate this by marking the correct box on the consent form. Towards the end of the research process you will also be invited back for another talanoa where we will discuss the themes that arise.

If you are happy for your child to participate in the study please complete the attached form, and your child will return it to their English teacher. Should you wish to contact my supervisors their email addresses are Cherie.chu@vuw.ac.nz and Gillian.hubbard@vuw.ac.nz.

Please note: this research has ethical approval from the VUW Faculty of Education Ethics Committee. Should you have any ethical concerns please contact Dr Allison Kirkman, Chair of the Human Ethics Committee. Allison.kirkman@vuw.ac.nz Ph: 044635676.

Kind regards,

Kalia Lautusi 


\section{Parent/Caregiver Information Sheet - Samoan}

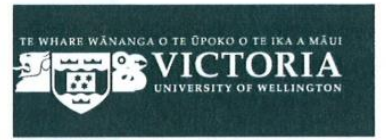

SCHOOL OF EDUCATION TE PUNA AKOPA

FACULTY OF EDUCATION TE WHĀNAU O AKO PAI

VICTORIA UNIVERSITY OF WELLINGTON, PO Box 17-310, Donald St, Karori, Wellington 6147, New Zealand Phone +64-4-4639500 Fax +64-4-4639649 Email education@vuw.ac.nz Web www.victoria.ac.nz/education

\section{Parent/caregiver Information Sheet \\ Research Project: Exploring how Year 10 Samoan students navigate teaching and learning in the English classroom.}

Talofa lava,

Mo lou silafia, o au o le faiaoga i le gagana peretania i le kolisi o Naenae i Ueligitone nei. I le taimi nei o loo ou sailiili mo a'u suesuega mo le faamae'aina o le Tusi pasi o le Master's thesis. Ua tuuina atu mo lou silafia se faatalatalanoaga mua mo lenei tuuaga, ma ua ou tuuina atu se talosaga pe mafai ona auai lou alo e tusa ai ma la'u suesuega. O lenei suesuega ma lona manulauti e faasaga lea i le malamalama'aga o tamaiti Samoa ma o latou aiga e faailoa ai lo latou atamai ma agatausili poo tomai, e avea ai ma ta'iala i le gagana peretania i totonu o le vasega.

O le manulauti o suesuega:

1. Ia lelei ona malamalama i le malosi'aga ma le atamai o Tamaiti Samoa i totonu o le vasega.

2. Ia malamalama lelei i ta'iala tamaiti Samoa e faaaoga auala ma aiaiga i le faaogaina o le gagana peretania i totonu o le vasega.

3. Oa ni vaega o le polokalame o le gagana peretania o loo faaogaina e tamaiti Samoa i loo latou auai ai, ma nisi o vaega o loo fai ma faafitauli ia latou.

E tusa ai ma lou maliega i le auai o lou alo ma a'u nei i vaega faapitoa e tolu o lenei suesuega, (e tasi mai i vaega o totoe o lenei vaituuaga faalea'oga o lenei tausaga) o le vaega lea o le a faatalanoa ai lo latou malosiaga ma agatausili poo tomai, ma faapefea ona latou faaaogaina le gagana peretania $\mathrm{i}$ totonu o le vasega. O le a fesiligia foi, e uiga $\mathrm{i}$ lona aiga, aua ni fesoasoani aoga o ia maua, atoa foi ma fesoota'iga e le aoga i le gagana peretania i vasega.

O le a iai tamaiti Samoa e toatolu e tofia mo vaega faapitoa e tolu, ma e onomea mo le 30 i le 60 minute. Mo le avanoa ua e tuuina mai, o le a ou taitai ina nei vaega faapitoa e tolu, i taimi ua faatulagaina ma alagatatau mo le faiaoga, poo taimi foi e avanoa ai lou alo ina ia aua nei misi avanoa e pei ona tuuina iai.

O le a sosoo ai ma lenei vaega faapitoa, o le a ou fesiligia ai loa tou alo taitoatasi, i le uma a'i ona ou mata'ituina lea o le vasega o le gagana Peretania. O lenei faatalatalanoaga e patino lava i vaega o le lesona sa fiafia iai, atoa ma ni latou mafaufauga i piriota eseese o nei lesona, mo le 20 ile 30 minute. O nei vaega faapitoa ma faatalatalanoaga e pu'eina ma faamauina. O le a mafai foi ona faaleoina ia taualumaga, e tatau ai ona sainia se maliega faalilolilo (confidentiality). $\mathrm{O}$ nei faamaumauga uma i auala faa televave - 
(electronics), e faaaogaina ai "password" poo se upu faapitoa e puipuia ai se faamatalaga, e mafai ai ona tatala faamaumauga. Ua na o au lava oute vaai iai i ia faamaumauaga atoa ma o'u faufautua mai i le Univesite o Vitoria o: Dr Gillian Hubbard ma Dr Cherie Chu. O nei faamaumauga uma a mae'a le poloketi, o le a tapeina aloa'ia ma faaleaogaina. E le toe iloa poo ai i latou na auai i mea uma. Oute tusitusi ma puipui i aia tatau a i latou o loo sa auai. Ma o i latou uma na auai pe le auai foi o le a le afaina ona tulaga tau aoaoina ma fuafuaga i soo se itu.

O le ua auai e fua i le loto malie e galue fua, ma e iai lau aia tatau e te toe suia ai lou auai i soo se taimi ae lei mae'a le aoina o faamauamauga, i le amataga lea o Novema 2015. E leai foi se toe Iloiloina e tuuina mai se mafuaaga ua mafua ai lea suiga. Ona o a'u o se faiaoga ua ou malamalama i le maualuga o le faatauaina e matua Samoa lona tulaga i le aoga tele ole aoaoina ma lona naunauta'i e galulue faatasi ma faiaoga, aua le tali sapaia ina o aoaoga ma lona taunuuga. I lou manatu la i lea itu ia ou faataua ma mautinoa le leai se faasea i finagalo o matua e ona tuuina atu ai le avanoa i lona alo e auai ma ni ona lagona fiafia e fesiligia ai au ina ia faamalamalamaina ni fesili o loo iai ia te oe. Afai o iai ni fesili, e mafai ona valaau mai au i le email: or

O faamaumauga o lenei suesuega e patino tonu ia te a'u (thesis)o le a lolomi ina, ma e alagatau ai ma ou fiafia e tuuina atu e fai ma faamatalaga i ni fono a i latou ua iai le atamai faa - faiaoga, faapea Tusitala (journals) e mafai ai ona fesoasoani i faiaoga o tamaiti Samoa aua le lumanai o o latou tomai faatufugaga. E le mafai foi ona faailoa lou alo e auala i lona igoa i soo se vaega o lenei ulutala poo le ripoti. Oute le faaogaina auala pu'eleo ma faamauina i soo se faasoa o lenei suesuega. E le mafai foi ona faailoa le igoa o le Kolisi o Naenae i soo se auala. Afai e te finagalo i sau kopi o lenei suesuega, faamolemole faailoa ane lou finagalo auai i le pusa ua uma ona tuuina atu i le pepa i lou finagalo malie. I le taunuuga o le suesuega, e valaau atu lau susuga mo se isi faatalanoaga aua nisi o ni mataupu fou ua fa'aalia.

Afai foi ua faamalieina lau susuga i le auai o lou alo i lenei suesuega, faamolemole faatumu ane le pepa ua tuuina atu, ma e mafai e lou alo ona toe alu i lana faiaoga o le gagana peretania. Afai ete finagalo e faafesoota'i ane o soo se tasi o komitio Faatufugaga, faamolemome faafesoota'i ane Dr Allison Kirkman, o ia o le faaulu o Tagata soifua ma Aga. (Chair of the Human Ethics Committee. Allison Kirkman@vuw.ac.nz. Ph 044635676.

Ma lou faaaloalo lava,

Kalia Lautusi. 


\section{Teacher Consent Form}

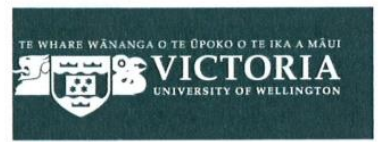

SCHOOL OF EDUCATION TE PUNA AKOPA

FACULTY OF EDUCATION TE WHĀNAU O AKO PAI

VICTORIA UNIVERSITY OF WELLINGTON, PO Box 17-310, Donald St, Karori, Wellington 6147, New Zealand

Phone +64-4-4639500 Fax +64-4-4639649 Email education@vuw.ac.nz Web www.victoria.ac.nzleducation

\section{Teacher Consent Form \\ Research project on Exploring how Year 10 Samoan students navigate teaching and learning in the English classroom}

- I have read the information letter and understand the purpose of the study.

- I understand the data gathering process

- I agree to participate in this research project through allowing three classroom observations.

- I understand that all data will be destroyed after the completion of the research.

- I understand that I may withdraw from this study at any time before the completion of data gathering in early November

- I understand I will receive a summary of the research findings for feedback before it is entered into the final report.

* If you have read, understood and agree to ALL points listed above tick the correct box below.

I consent to participating in this research

I do not consent to participating in this research

Email address

Principal's Name:

Principal's Signature:

Date:

Please complete this form and return it to me by [date] 2015 


\section{Teacher Information Sheet}

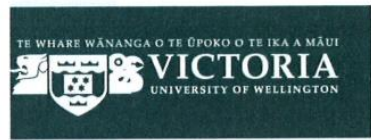

SCHOOL OF EDUCATION TE PUNA AKOPAI

FACULTY OF EDUCATION TE WHĀNAU O AKO PAI

VICTORIA UNIVERSITY OF WELLINGTON, PO Box 17-310, Donald St, Karori, Wellington 6147, New Zealand

Phone +64-4-4639500 Fax +64-4-4639649 Email education@vuw.ac.nz Web www.victoria.ac.nz/education

\section{Teacher Information Sheet \\ Research Project: Exploring how Year 10 Samoan students navigate teaching and learning in the English classroom.}

Talofa lava,

I am currently conducting a research project as part of my Masters of Education at Victoria University. The research is to explore how Samoan students and their families perceive their own strengths and skills, and how they use these to navigate teaching and learning in the English classroom.

The objectives of the study are:

1. To better understand the strengths and skills Samoan students bring with them to the classroom.

2. To better understand the strategies Samoan students use when navigating instructions and learning tasks in the English classroom.

3. To better understand which parts of the English programme Samoan students find the most engaging, and which parts they find most frustrating.

As part of this research I wish to gather student voice focusing on how they see themselves both inside and outside of the English classroom, and their perceived strengths and barriers. I am focusing on Year 10 students and as your class [class name] has a high percentage of Samoan students I would like to invite you to participate in this study by allowing three classroom observations of this class.

The observations will be a supplement to the information I gather during an earlier focus group with six students from your English class. If you agree, I will observe three lessons (one in each remaining term of the 2015 school year). The observations will be done during a time that is convenient to you, you will not be required to change any learning task or teaching routines. After the observations I will then individually ask students questions based around the lesson, and what their thoughts were during different tasks.

During the observation I will be taking handwritten notes on student interactions, behaviour and participation. To help with accuracy I will also be using an audio recorder. All electronic information will be kept in a password-protected file and will be restricted to me and my two Victoria University advisors, Dr Gillian Hubbard and Dr Cherie Chu. All recordings will be deleted after the project is complete. No recorded information will identify who you are, as I will change all names in anything I write to protect participants' privacy. 
Participation is voluntary and you will have the right to withdraw at any time before the end of the data collection time, which will be early November 2015. You will not be required to provide any reason for withdrawing. Classroom observations will only be conducted with your permission and you are not required to discuss the lesson with me, but feel free to share your thoughts if you wish to.

The findings of this study will be published in my thesis and may also be used to make presentations at conferences of educators, and write papers for publication in academic journals. You will not be identified by name in any presentation or report. I will not use the audio recordings at any such presentation. Your school will also not be identified by name in any presentation. Should you wish to receive a copy of the main findings, please indicate this by marking the correct box on the consent form.

If you are happy to participate please indicate this by marking the correct box on the consent form and return to me. If you have any questions at all, you can contact me via email a Should you wish to contact my supervisors their email addresses are Cherie.chu@vuw.ac.nz and Gillian.hubbard@vuw.ac.nz.

Please note: this research has ethical approval from the VUW Faculty of Education Ethics Committee. Should you have any ethical concerns please contact Dr Allison Kirkman, Chair of the Human Ethics Committee. Allison.kirkman@vuw.ac.nz Ph: 044635676.

Kind regards,

Kalia Lautusi 


\section{Principal Consent Form}

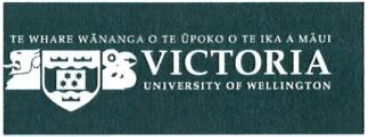

SCHOOL OF EDUCATION TE PUNA AKOPAI

FACULTY OF EDUCATION TE WHĀNAU O AKO PAI

VICTORIA UNIVERSITY OF WELLINGTON, PO Box 17-310, Donald St, Karori, Wellington 6147, New Zealand Phone +64-4-4639500 Fax +64-4-4639649 Email education@vuw.ac.nz Web www.victoria.ac.nz/education

\section{Principal Consent Form \\ Research project on Exploring how Year 10 Samoan students navigate teaching and learning in the English classroom}

- I have read the information letter and understand the purpose of the study.

- I understand the purpose of the data gathering process

- I consent to the participation of Naenae College in this research project.

- I consent to staff and students of Naenae College being involved.

- I understand that all data will be stored in secure folders and will be destroyed after the completion of the research.

- I understand I will receive a summary of the research findings for feedback before it is entered into the final report.

* If you have read, understood and agree to ALL points listed above tick the correct box below. Please be aware participants are able to withdraw from the study at any time before the end of the data collection phase. No reason will need to be provided for withdrawing.

I consent to Naenae College's involvement in this research project

I do not consent to Naenae College's involvement in this research project

Email address

Principal's Name:

Principal's Signature:

Date: 


\section{Principal/BOT Information Sheet}

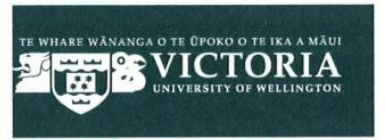

SHOOL OF EDUCATION TE PUNA AKOPAI

FACULTY OF EDUCATION TE WHĀNAU O AKO PAI

VICTORIA UNIVERSITY OF WELLINGTON, PO Box 17-310, Donald St, Karori, Wellington 6147, New Zealand Phone +64-4-4639500 Fax +64-4-4639649 Email education@vuw.ac.nz Web www.victoria.ac.nzleducation

\section{Principals/BOT Information Sheet \\ Research Project: Exploring how Year 10 Samoan students navigate teaching and learning in the English classroom.}

Talofa lava,

I am currently conducting a research project as part of my Masters of Education at Victoria University. The research is to explore how Samoan students and their families perceive their own strengths and skills, and how they use these to navigate teaching and learning in the English classroom.

The objectives of the study are:

1. To better understand the strengths and skills Samoan students bring with them to the classroom.

2. To better understand the strategies Samoan students use when navigating instructions and learning tasks in the English classroom.

3. To better understand which parts of the English programme Samoan students find the most engaging, and which parts they find most frustrating.

The purpose of this study is to understand what is happening in the English classroom for both first and second generation Samoans through the students' perspective, and how educators can use Samoan students' strengths as a support in improving learning outcomes. The research will also provide parents of these learners an opportunity to describe the strengths and skills they have witnessed, and encourage parents to participate in discussions about the aspirations they have for their children.

The project will involve collecting information through:

- Talanoa sessions (informal focus groups) with parents of participants

- Talanoa sessions (informal focus groups) with students

- Talanoa sessions will be held at your institution, at a time agreed with yourself, the participants and teachers. Sessions would be scheduled so as not to disrupt individual students and staff time. The students and staff will be able to stop the session and withdraw from it at any time if they so wish and will be informed of this before the session commences.

- One classroom observation for each of the remaining school terms (of both $10 \mathrm{~N}$ and $10 \mathrm{H}$ ).

Participation is voluntary and both teacher and students will have the right to withdraw at any time before the end of the data collection time, which will be early November 2015 . They will not be required to provide any reason for withdrawing. All parents will be approached informally via telephone or directly, then invited to a talanoa session to clarify 
the research project and what will be involved. During this session I will ask parents to discuss participation in the study with their children, shortly following the initial talanoa session I will discuss the research with the students provide an information sheet and consent form. Both the parents and the students must consent before an data gathering begins.

The findings of this study will be published in my thesis and may also be used to make presentations at conferences of educators, and write papers for publication in academic journals. No participant will be identified by name in any presentation or report. I will not use the audio recordings at any such presentation. Your school will also not be identified by name in any presentation or report. Should you wish to receive a copy of the main findings, please indicate this by marking the correct box on the consent form.

I would like to request your consent to Naenae College's involvement in the project. If you agree to this request we would appreciate it very much if you would sign and date the consent form attached and return to me. You will not be required at talanoa sessions or for interviewing but are most welcome to attend the talanoa session with aiga/family.

If you have any questions at all, you can contact me via email at

Should you wish to contact my supervisors their email addresses are

Cherie.chu@vuw.ac.nz and Gillian.hubbard@vuw.ac.nz.

Please note: this research has ethical approval from the VUW Faculty of Education Ethics Committee. Should you have any ethical concerns please contact Dr Allison Kirkman, Chair of the Human Ethics Committee. Allison.kirkman@vuw.ac.nz Ph: 044635676.

Kind regards,

Kalia Lautusi 